\title{
El concepto unitario de incumplimiento en el moderno derecho de contratos*
}

\author{
The Unitary Concept of Breach of Contract in Modern Contract Law
}

\author{
Jorge Oviedo Albán a \\ Universidad de La Sabana, Colombia \\ jorge.oviedo@unisabana.edu.co \\ ORCID: https://orcid.org/0000-0003-2174-4765
}

Álvaro Vidal Olivares

Pontificia Universidad Católica de Valparaiso, Chile

ORCID: https://orcid.org/0000-0001-5362-9310
DOI: https://doi.org/10.11144/Javeriana.vj69.cuim

Recibido: 19 Diciembre 2019

Aceptado: 09 Enero 2020

Publicado: 30 Diciembre 2020

\section{Resumen:}

A partir de la identificación del fraccionamiento de remedios por incumplimiento contractual — como un problema normativo existente en los Códigos Civil y de Comercio colombianos-, en este artículo se aborda la posibilidad de formular un concepto unitario de incumplimiento y remedios, a los cuales el acreedor pueda acudir para satisfacer sus intereses. El modelo planteado por los autores, sobre la base de una revisión de los instrumentos internacionales que conforman el nuevo derecho de contratos, se caracteriza por establecer un sistema unitario de remedios de común aplicación a las distintas hipótesis constitutivas de incumplimiento. Esta mirada al modelo permite una relectura e interpretación de las normas sobre incumplimiento de los códigos de Derecho Privado, ya que hace posible alcanzar soluciones acordes con las actuales condiciones del tráfico y, por encima de todo, disipar las perplejidades que provoca la disciplina. De esta manera, ofrece una construcción dogmática de la noción de incumplimiento, no solo en el plano de lege lata, sino en el de la aplicación de las normas para la resolución de los conflictos contractuales.

Palabras clave: incumplimiento, remedios, contratos, obligaciones.

\begin{abstract}
:
The dispersion of remedies accounts for the contractual breach as a normative issue found in the Civil and Commercial Codes of Colombia. This paper will consider the concept of a contractual breach capable of arranging a set of remedies to the creditor to satisfy his interests. The model proposed by the authors, constructed over the review of the instruments of soft law that constitute the new contract's law, offers a unitarian system of remedies of the common application for the different scenarios of contractual breach. This approach to the model allows a new lecture and interpretation of the rules that govern the cases of contractual breach in the private law codes by delivering appropriate solutions regarding the commercial traffic and blurring the perplexities generated by the current regulation. It also offers a dogmatic conceptualization of the contractual breach, not only as a proposal of modification of the rules but as a direct application to solving contractual disputes.
\end{abstract}

Keywords: breach of contract, remedies, contracts, obligations.

\section{Introducción}

Este artículo parte de la identificación de un problema normativo en los Códigos Civil y de Comercio de Colombia, que consiste en la presencia de un sistema fraccionado y disperso de medios de protección del acreedor ante situaciones constitutivas de incumplimiento contractual. Esto produce un efecto práctico complejo y no deseado, pues el afectado se enfrenta a la incertidumbre de un medio de tutela, que tienda a la satisfacción de su interés lesionado. Este hecho consiste en la ausencia de un concepto general de incumplimiento y, por ende, de una estructura unitaria de medios de protección para el acreedor ${ }^{1}$.

Es cierto que algunos autores se han apoyado en normas, como los artículos 1613 y 1614 del Código Civil, que regulan el contenido de la indemnización por incumplimiento de las obligaciones contractuales, con

Notas de autor

a Autor de correspondencia. Correo electrónico: jorge.oviedo@unisabana.edu.co 
el fin de establecer que esta comprende el daño emergente y lucro cesante - ya sea por no haber cumplido la obligación, haberla cumplido incorrectamente, o haberse tardado en su cumplimiento-, para destacar que estas situaciones constituyen incumplimiento del contrato ${ }^{2}$. Aunque, de todos modos, el cumplimiento imperfecto o defectuoso es un asunto que ha sido olvidado por la doctrina, puesto que solo se ha enfatizado en la no ejecución de la obligación y el cumplimiento tardío ${ }^{3}$.

Ante las mencionadas situaciones constitutivas de incumplimiento, también se parte de afirmar que los derechos principales del acreedor insatisfecho, o medios de satisfacción del crédito ${ }^{4}$, consisten en la ejecución forzosa de la prestación no ejecutada, que busca constreñir al deudor al cumplimiento de la prestación, al igual que a la obtención de la indemnización de perjuicios, o bien la resolución o terminación del contrato. Esto se apoya en los artículos 1546 del Código Civil (ubicado en el título IV "De las obligaciones condicionales y modales", del libro IV), y 870 del Código de Comercio (norma que se encuentra en el capítulo IV "El contrato en general" del Libro IV), además de las manifestaciones particulares para la inejecución de las obligaciones de hacer y no hacer, establecidas en los artículos 1610 y 1612 del Código Civil, (normas que se encuentran ubicadas en el título XII "Del efecto de las obligaciones" del Libro IV) 5 . Pero basta una lectura de las reglas establecidas en los capítulos sobre contratos en particular, para advertir que también existen acciones especiales frente a supuestos de incumplimiento, sin que exista claridad, ni en la doctrina ni en la jurisprudencia, sobre la forma como se articulan tales acciones.

Si bien lo deseable es que un nuevo Código de Derecho Privado corrigiese tal defecto normativo, mientras ello no suceda, es posible plantear una relectura de las normas vigentes. Por un lado, es posible a partir de una mirada al modelo del derecho uniforme y armonizado de contratos, con o sin fuerza de ley, como la Convención de Naciones Unidas sobre Compraventa Internacional de Mercaderías (en adelante la CISG), y la reforma al Code Civil de 2016 en materia de contratos y obligaciones (en adelante la reforma francesa) ${ }^{7}$. Y por el otro lado, por medio de los Principios de UNIDROIT sobre Contratos Comerciales Internacionales (en adelante los PCCI), los Principios Europeos de Derecho de Contratos (en adelante los PECL), y los recientes Principios Latinoamericanos de Derecho de Contratos (en adelante los PLDC), como también una aplicación directa de los mismos ${ }^{8}$. Todos estos instrumentos conforman lo que se denomina el nuevo derecho de contratos ${ }^{9}$ que, entre otros aspectos, se caracteriza por establecer un sistema unitario de remedios de común aplicación a las distintas hipótesis constitutivas de incumplimiento.

Esta mirada al modelo permite una relectura e interpretación de las normas sobre incumplimiento de los códigos de derecho privado, pues posibilita alcanzar soluciones acordes con las actuales condiciones del tráfico y, por encima de todo, disipa las perplejidades que provoca la disciplina que ellos contienen - si es que es posible hablar de una disciplina. Se trata de ofrecer una construcción dogmática de la noción de incumplimiento, no solamente en el plano de lege lata, sino en el de la aplicación de las normas para la resolución de los conflictos contractuales. Sobre este punto, ha de llamar la atención que tanto los PCCI, como los PECL y los PLDC reconocen entre sus funciones el servir de dispositivo para la interpretación o complementación de los derechos internos ${ }^{10}$. En efecto, en el preámbulo de los PCCI, titulado "Propósito de los principios", se indica que estos pueden ser utilizados para interpretar o complementar el derecho nacional. Es similar la fórmula empleada en el artículo 2 de los PLDC, cuyo numeral $2^{\circ}$ establece que "Estos Principios se aplican para interpretar instrumentos internacionales de derecho uniforme y derecho estatal que rigen el contrato". Así las cosas, esta fórmula puede permitir que, al igual que ha sucedido con otros instrumentos de soft law, los jueces, árbitros y abogados, puedan encontrar en los PLDC elementos de apoyo para la interpretación y aplicación de los instrumentos internacionales, o leyes nacionales que resultaren aplicables a los contratos.

De manera adicional, corresponde puntualizar que el vocablo remedios se traduce de la expresión angloamericana remedies, y que el sistema del Common Law permite agrupar funcionalmente las consecuencias que se siguen para la parte que ha incumplido el contrato - sea porque no se ha cumplido o se 
ha cumplido de manera defectuosa-; a su vez, hace alusión a los mecanismos de tutela de los cuales dispone el acreedor ${ }^{11}$. La expresión remedios ha sido ampliamente acogida por la doctrina del derecho civil continental y, al igual que en el Common Law, sirve para aludir a los derechos, pretensiones o acciones, de los que dispone el acreedor frente al incumplimiento del deudor ${ }^{12}$. Así, por ejemplo, Morales Moreno, señala que:

El término remedio designa, en general, una medida de protección que el Ordenamiento jurídico ofrece a un sujeto, cuanto este sufre la lesión de un interés digno de protección jurídica. En el incumplimiento, el término remedios designa las medidas de protección que el Ordenamiento pone a disposición del acreedor insatisfecho, en caso de incumplimiento del contrato ${ }^{13}$.

El autor agrega que, aunque este término no tiene arraigo histórico en la tradición jurídica continental, este es más flexible, y no está contaminado por la construcción judicialista que históricamente ha acompañado a las medidas de protección del derecho de contratos ${ }^{14}$. Esta expresión es empleada en la versión en inglés de la $\mathrm{CISG}^{15}$,. Aunque en la versión oficial en castellano no se emplea la palabra remedios, sino derechosy acciones en caso de incumplimiento, tanto del vendedor como del comprador; algunos autores la traducen como remedios ${ }^{16}$. De igual manera, se emplea en el artículo 3.2.4 de los Principios de Unidroit, la cual está traducida como remedios en la versión en castellano ${ }^{17}$. Otros autores la utilizan para aludir al sistema de acciones, sanciones o recursos, de los que dispone el acreedor ante el incumplimiento del deudor, contenidos tanto en otros instrumentos uniformes, como en regulaciones nacionales ${ }^{18}$.

Con base en lo anterior, este artículo tiene por objeto identificar las bases sobre las cuales se puede construir un concepto unitario de incumplimiento contractual y, a partir de ello, poder determinar sus consecuencias. Estas consisten en la construcción de un sistema unitario de remedios a los cuales el acreedor insatisfecho pueda acudir.

Para ello, este artículo está estructurado de la siguiente forma: en primer lugar, se identifica el problema normativo que presentan el Código Civil y de Comercio colombianos, que regulan una acción resolutoria por incumplimiento de alcance restringido, a partir de una norma que consagra la denominada condición resolutoria tácita. En segundo lugar, se da claridad sobre el concepto unitario de incumplimiento, y se muestran las bases con las que se puede construir en el Código Civil. En tercer lugar, se refiere el panorama del incumplimiento en el moderno derecho de contratos. En cuarto lugar, se expone la concepción realista de contrato, cuya consecuencia principal es la construcción de un sistema unificado de remedios. Finalmente, se evidencia la situación consistente en el fraccionamiento de situaciones de incumplimiento y remedios en los Códigos de Derecho privado colombianos. Estas últimas pueden superarse por vía interpretativa si se acoge la concepción realista del contrato y sus consecuencias. Con ello, permite ser construido a partir de una relectura, en clave moderna, de las reglas existentes en los Códigos.

\section{El modelo: el incumplimiento en el moderno derecho de contratos}

En el Derecho uniforme de la contratación, manifestado en la CISG, en los Principios de Unidroit sobre contratos comerciales internacionales, los Principios europeos de derecho de contratos, y los Principios Latinoamericanos de Derecho de los Contratos, se adopta una noción unitaria, amplia y objetiva de incumplimiento, que comprende toda manifestación de inejecución contractual. Excluye la exoneración de responsabilidad de parte del deudor y no solo comprende la inejecución de deberes de conducta de parte del deudor, sino también la ausencia de determinados estados o situaciones presupuestos en el contrato y garantizados por él ${ }^{19}$. En este modelo, se prescinde del estándar del buen padre de familia y de la culpa; a pesar de ello, la conducta del deudor se aprecia conforme con un estándar más exigente: el de la persona razonable ${ }^{20}$.

En efecto, basta revisar los artículos 45 y 61 de la CISG para advertir que estas normas consagran los remedios de los que dispone el acreedor ante el incumplimiento de cualquiera de las obligaciones del deudor ${ }^{21}$. 
A su vez, el artículo 25 de la CISG define el incumplimiento esencial del contrato como aquel que cause a la otra parte un perjuicio, un perjuicio tal que la prive sustancialmente de su lo que tenía derecho a esperar en virtud del contrato, salvo que la parte que haya incumplido no hubiese previsto tal resultado, y que una persona razonable de la misma condición no lo hubiera previsto en igual situación. Este concepto tomado del Common Law distingue entre incumplimiento esencial y no esencial, donde la resolución del contrato se reserva para el primero - con la consideración de gravedad por parte de un juez-, de forma que, si afecta la base del contrato, frustra la finalidad perseguida por la parte afectada o priva sustancialmente de la satisfacción del interés pretendido; el acreedor puede resolverlo ${ }^{22}$.

En la CISG, para que el incumplimiento se pueda calificar como esencial, debe mirarse la manera en que han sido afectadas las expectativas contractuales del acreedor, las cuales se deben privar de forma sustancial; esto es que se genere una lesión contractual grave ante lo cual el acreedor pierda interés en el contrato ${ }^{23}$. El artículo 49 de la Convención reconoce el derecho del comprador a declarar resuelto el contrato, si el incumplimiento por el vendedor de las obligaciones que le incumban puede ser calificado como esencial. Cabe recordar que según el artículo 26, la declaración de resolución no requiere pronunciamiento judicial, pues basta que el acreedor se la comunique a la otra parte. Se diferencia de lo que sucede normalmente en los Códigos de la tradición europea, en los cuales la resolución debe declararla el juez, para lo cual corresponde al acreedor interponer una acción declarativa. Esto también sucede en Colombia y Chile, según lo establecido en los artículos 1546 y 1489 de los respectivos códigos civiles vigentes en ambos países.

Adicionalmente, según el numeral $2 \mathrm{~b}$, la posibilidad de decretar la resolución por incumplimiento esencial, en caso de falta de conformidad, debe hacerse dentro de un plazo razonable después de que haya tenido o debiera haber tenido conocimiento del incumplimiento o después del vencimiento del plazo suplementario, en los casos en que este se haya fijado.

El artículo 79 (5) de la CISG limita el ámbito de aplicación de la causa de exoneración a la indemnización de daños, pues permite que el acreedor haga uso de los demás remedios, como son la resolución, la reparación o la rebaja del precio ${ }^{24}$. Corresponde precisar que en este régimen hay incumplimiento, a pesar de que el deudor se encuentre amparado por la causa de exoneración del citado artículo 79 (1) de la CISG. Ahora, si bien es cierto que la CISG no incluye un concepto de incumplimiento, hace una referencia implícita a que este se origina en la no realización de las obligaciones de las partes, o bien un cumplimiento defectuoso o tardío de las mismas ${ }^{25}$. No obstante, debe ser claro que en el contexto de la CISG no se hace referencia al incumplimiento de obligaciones aisladamente consideradas, sino del contrato. Entonces, se entiende que este se incumple cuando se produce la insatisfacción del interés contractual del acreedor, lo que abarca tanto la falta de cumplimiento en sí mismo, como el cumplimiento tardío o defectuoso ${ }^{26}$.

Ello se deduce de las normas que regulan los remedios a los que puede acudir el acreedor afectado, los cuales se fundan en los siguientes supuestos: la no entrega del bien por parte del vendedor ${ }^{27}$; el no pago del precio por el comprador ${ }^{28}$; y la falta de conformidad jurídica o material (no libre de pretensiones de terceros o cuando sirva defectuosamente $)^{29}$. De esta manera, la CISG permite entrever que los supuestos que lo constituyen son: la no ejecución de las obligaciones y la falta de entrega de parte del vendedor ${ }^{30}$, o de pago del precio de parte del comprador $^{31}$; y el cumplimiento tardío y defectuoso, manifestado en las reglas sobre falta de conformidad jurídica o material ${ }^{32}$.

Los PCCI incluyen una definición de incumplimiento. En efecto, este indica que el incumplimiento "consiste en la falta de ejecución por una parte de alguna de sus obligaciones contractuales, incluyendo el cumplimiento defectuoso o tardío" ${ }^{33}$. A partir de esto, establecen los remedios derivados de ello: sección 2, derecho a reclamar el cumplimiento ${ }^{34}$; sección 3 , resolución $n^{35}$; y sección 4, resarcimiento ${ }^{36}$. En los PCCI se prescinde de la noción de culpa, aunque, al igual que en la CISG, se prevé una causa de exoneración. Si el deudor acredita la concurrencia de esta causa, igualmente habrá incumplimiento y el acreedor puede hacer 
uso de cualquier remedio distinto a la indemnización de daños o el cumplimiento específico ${ }^{37}$. Así entonces, al igual que lo sucedido en la CISG, en los PCCI el concepto es simplificador y aglutinador de las distintas modalidades del incumplimiento ${ }^{38}$.

Por su parte, el artículo 1301 (4) del PECL define el incumplimiento como "cualquier incumplimiento de una obligación derivada del contrato, esté o no justificada, e incluye el cumplimiento tardío o defectuoso, así como la inobservancia del deber de colaborar para que el contrato surta plenos efectos" ${ }^{39}$. En los PECL, el incumplimiento comprende cualquier desviación del cumplimiento, desde la total inactividad del deudor hasta cualquiera falta de conformidad ${ }^{40}$. Esta noción de incumplimiento, tal como lo manifiesta Morales Moreno, también comprende los casos de imposibilidad inicial, porque no se predica de la conducta debida del deudor (en cuyo caso podría pensarse "impossibilium nulla obligato est"), sino del contrato, pues significa la falta de realización de este. El incumplimiento pone de manifiesto el problema de insatisfacción del interés del acreedor y abre el camino a la respuesta del ordenamiento —orientada al reparto de ese riesgo entre los contratantes-, a través del sistema de remedios que integran el contenido de la responsabilidad contractual (en el sentido amplio que él emplea $)^{41}$.

En los PLDC, el incumplimiento del contrato se trata en el capítulo 8, que a su vez está dividido en tres secciones: la primera, sobre el incumplimiento, definición y causas; la segunda, referida a los medios de tutela del acreedor; y la tercera, sobre las condiciones de procedencia, ejercicio y efectos de los medios de tutela particulares $^{42}$.

El incumplimiento se encuentra definido en el artículo 86 de los PLDC así:

1. Incumplimiento es la falta de ejecución del contrato en la forma pactada.

2. El cumplimiento imperfecto comprende toda disconformidad entre lo acordado y lo ejecutado por el deudor.

3. El incumplimiento del deudor comprende el hecho de las personas que emplee para la ejecución.

Como se puede advertir, este acoge un concepto de incumplimiento que abarca tanto la no realización de lo convenido, como su ejecución o cumplimiento imperfecto. Estos, a su vez, tienen cabida en situaciones de cumplimiento parcial, tardío o que presente anomalías, ya sea de carácter material o jurídico, lo cual requiere una comparación entre lo acordado (objeto ideal), y lo ejecutado (objeto real), de tal manera que, si el segundo no coincide con el primero, hay incumplimiento. Además, este concepto no solo comprende el hecho del deudor, sino también el de sus auxiliares o, en general, de las personas empleadas por este para su cumplimiento ${ }^{43}$.

$\mathrm{Al}$ igual que lo acaecido en otros instrumentos modernos, en los PLDC el incumplimiento se constituye como un hecho amplio y objetivo. Esto es porque abarca situaciones que, en los códigos de la tradición europea, se encuentran regulados de manera fraccionada en regímenes especiales, como son los de saneamiento por evicción y vicios ocultos, además de la imposibilidad según la forma como se encuentra regulada en el artículo $90^{44}$.

En cuanto al carácter objetivo del incumplimiento en los PLDC, este se manifiesta en el hecho de que no importa si el mismo se originó en una conducta del deudor, del acreedor o sus auxiliares, o un impedimento proveniente del caso fortuito o la fuerza mayor. En estas situaciones corresponde determinar los medios de tutela de los cuales podrá disponer el acreedor. Así, si el incumplimiento se genera en una acción del acreedor o sus auxiliares, se le priva de la posibilidad de acudir a tales medios consagrados en el artículo 91. Según lo que dispone el artículo 88, si se trata de una situación de imposibilidad proveniente de caso fortuito o fuerza mayor, el acreedor no podrá reclamar una indemnización por los perjuicios derivados, según el artículo $104^{45}$.

También cabe destacar que la reforma francesa ha introducido una noción unitaria de incumplimiento, y de medios de tutela para el acreedor, pues generaliza algunos remedios que figuraban en las reglas particulares de ciertos contratos, como es el caso de la suspensión y la reducción del precio en la compraventa ${ }^{46}$. En efecto, 
el nuevo artículo 1217 del Code establece que el acreedor, a quien no se le ha cumplido o lo ha sido de forma imperfecta, puede interponer cualquiera de los siguientes remedios: negarse a cumplir o suspender el cumplimiento de su obligación, perseguir la ejecución forzada de la misma, obtener una reducción del precio, provocar la resolución del contrato, o demandar la reparación de las consecuencias de la inejecución ${ }^{47}$.

En definitiva, puede advertirse cómo los instrumentos que conforman el moderno derecho de contratos acogen un concepto unificador que comprende todas las manifestaciones del incumplimiento ${ }^{48}$. No se limita a la inejecución de las prestaciones contractuales, sino también la insatisfacción de los intereses del acreedor - por la falta de verificación del estado de cosas asumido por los contratantes-. Se caracteriza, además, por ser objetivo al prescindir del elemento culpa como criterio de imputación de la responsabilidad del deudor. En la doctrina francesa moderna, Genicón afirma que el incumplimiento se define de mejor forma en un sentido negativo, como el no cumplimiento de una obligación impuesta por el acuerdo de las partes, por lo que resulta erróneo atar de manera sistemática la noción de incumplimiento con la de culpa ${ }^{49}$.

Así pues, el derecho moderno de la contratación acoge una noción amplia y objetiva de incumplimiento, que tiene la virtud de abarcar todo tipo de infracción de la regla contractual. Además, sirve para construir un sistema de responsabilidad contractual en el cual resulta irrelevante si el deudor resulta o no exonerado de responsabilidad ${ }^{50}$.

Ahora bien, la pregunta que ha de plantearse al llegar a este punto es: ¿resulta posible construir en los códigos de derecho privado una noción unitaria de incumplimiento, similar a la del moderno derecho de contratos? Para resolver esta inquietud, resulta necesario indagar sobre el alcance de una concepción realista del contrato, que se construye a partir de la identificación del propósito práctico del acreedor. A su vez, averiguar si existen bases, tanto en el Código Civil como en la jurisprudencia, para el desarrollo de esta concepción, lo que permitirá analizar la posibilidad de construir un concepto amplio de incumplimiento, aspectos que serán desarrollados en los puntos siguientes.

\section{La concepción realista del contrato, el propósito práctico del acreedor}

Constituye un lugar común en la doctrina europea referirse, en términos más o menos similares, al contrato como un acuerdo de voluntades, generador de obligaciones. En este sentido, el concepto de contrato que proporciona el Código Civil colombiano corresponde a una noción normativa del mismo, que considera exclusivamente los derechos y obligaciones que produce: "Contrato o convención es un acto por el cual una parte se obliga para con otra a dar, hacer o no hacer alguna cosa”. Como se advierte, esta norma se basa en un modelo de vinculación contractual, tradicionalmente adoptado por los códigos decimonónicos, y que la entiende por prestación, es decir: la conducta que debe realizar el deudor a favor del acreedor ${ }^{51}$.

$\mathrm{Al}$ igual que el concepto de obligación limitado a la prestación, esta noción de contrato es insuficiente para explicar el fenómeno negocial y, por ello, también el de incumplimiento ${ }^{52}$. Este modelo ofrece ciertos inconvenientes: por ejemplo, dificulta que las cualidades materiales y jurídicas, que debe poseer la cosa para satisfacer el interés del comprador, sean contenido de la prestación, y su ausencia pueda considerarse incumplimiento. De igual manera, complica la articulación de la pretensión de subsanación —manifestada ya sea en la reparación o la sustitución, en casos de cumplimientos defectuosos-, al exceder la prestación del vendedor que originariamente es de dar y no de hacer.

Tal pretensión rebasa el contenido originario de la prestación ${ }^{53}$. Hay que tener en cuenta que, con el contrato, las partes persiguen un propósito práctico que permite satisfacer su interés en el cumplimiento, el cual es relevante en la medida que esté incorporado al acuerdo. Por ello, la noción normativa debe complementarse con la concepción realista. Como consecuencia, la visión tradicional con la cual el acreedor, en virtud de su derecho subjetivo de crédito, puede lograr un comportamiento del deudor en caso de incumplimiento, resulta superada si se asume que tal derecho no consiste propiamente en lograr un 
comportamiento del deudor, sino en obtener la satisfacción de un determinado fin o interés, por lo que el incumplimiento se configura cuando este no se satisface.

De esta forma, los problemas de incumplimiento del contrato deben tratarse como cuestiones de satisfacción e insatisfacción del acreedor, y no solamente de inejecución de las obligaciones ${ }^{54}$. Además, esta concepción permite concluir que, si el deudor garantiza un resultado, la vinculación que genera el contrato entre las partes no solo incluye obligaciones, entendidas nuevamente como prestaciones o deberes de comportamiento exigibles, sino también ciertas presuposiciones relativas a hechos, situaciones o estados de la realidad, cuyo riesgo de existencia o inexistencia es asumido por el deudor". Por ello, esta "concepción realista" de contrato, centrada en el "propósito práctico" perseguido por las partes, busca la redefinición de la problemática de las cualidades de la $\operatorname{cosa}^{56}$. Asume que, si el negocio jurídico se concibe como un medio de satisfacción de intereses de las partes, puede no alcanzar su objetivo por causas que, en ocasiones, pueden imputarse o no a la conducta de estas, al abarcar situaciones que no solamente incluyen el incumplimiento, sino también el error además de los vicios ocultos, lo cual permite construir el sistema unitario de remedios ${ }^{57}$, concebidos como mecanismos de los que dispone el acreedor para satisfacer su interés ${ }^{58}$.

El intérprete - juez o árbitro-, al definir este propósito práctico, lo conectará necesariamente con la causa del contrato, estipulada en el inciso segundo del artículo 1524 del CC., ya no para medir la moralidad o legalidad del acto, sino sus efectos derivados del incumplimiento ${ }^{59}$. Este sistema propuesto corresponde con el que han asumido los instrumentos de modernización ya mencionados ${ }^{60}$.

Esta manera de concebir el contrato hace necesario revisar el alcance de la fuerza obligatoria del mismo, que tradicionalmente ha permitido sostener que, ante el incumplimiento, el acreedor debe buscar el cumplimiento por sobre las otras alternativas en vista del supuesto principio de pervivencia del contrato. Si el contrato persigue la satisfacción del interés del acreedor, y este se incumple, sus efectos deben apuntar a la protección de ese interés insatisfecho, perteneciendo a esa parte, víctima del incumplimiento, la opción entre dicho cumplimiento u otra acción que conduzca a su satisfacción.

En la jurisprudencia colombiana, se encuentran algunos fallos que recogen la noción realista de contrato cuando se revisa la finalidad o propósito de las partes al contratar, al definir los efectos del incumplimiento; a partir de ello, se califica como esencial y se gradúa el sistema de acciones del acreedor. Particularmente, puede destacarse un fallo de la Corte Suprema de $2009^{61}$, en el que las premisas sentadas pueden servir de parámetros para que posteriores sentencias solucionen por vía interpretativa algunos problemas legislativos que se viven en el derecho colombiano. Estos dilemas resultan comunes en varias legislaciones de la tradición del Derecho Civil, como es la coexistencia de remedios frente a situaciones que configuran incumplimiento contractual, tales como los vicios redhibitorios en la compraventa, los defectos de cantidad, entre otros.

La sentencia de 18 de diciembre de 2009 se dictó a propósito de los siguientes hechos: en virtud de un contrato de venta de un establecimiento de comercio, se demandó a la compradora para que restituyera el bien objeto del contrato, y se pagaren los frutos percibidos (o que hubiese podido percibir), desde la fecha de recepción de este, incluyendo la pena pactada con intereses moratorios. En subsidio, se solicitó la resolución por incumplimiento de ambas partes. Las contratantes habían suscrito un acuerdo privado, en virtud del cual convinieron celebrar el contrato de venta del establecimiento por escritura pública en fecha posterior. Según la demandante, la contraparte incumplió con la forma de pago pactada en el contrato. La vendedora concurrió a suscribir la escritura pública en la fecha pactada, pero se abstuvo de hacerlo ante el incumplimiento de la compradora. Tras la reclamación, la demandada formuló la excepción de contrato no cumplido. En primera instancia se declaró resuelto el contrato de compraventa por mutuo incumplimiento, y se condenó a la demandada a restituir el establecimiento, y a la demandante a devolver la parte del precio que había recibido.

Las dos partes apelaron el fallo. El Tribunal de apelación negó la excepción de contrato no cumplido, declaró resuelto el contrato por incumplimiento de la demandada, y ordenó las restituciones mutuas correspondientes. La Corte aceptó el recurso de casación interpuesto por violación de diversas normas 
probatorias, revocó la sentencia dictada por el juez de primera instancia, y desestimó las pretensiones del demandante.

La Corte comprobó que la compradora cumplió tardíamente lo pactado, y entró a analizar si en este caso cabía la acción de resolución del contrato. Sobre este punto, indicó que el incumplimiento que da lugar a la facultad de resolver el contrato debe cumplir ciertos requisitos para ser calificado como resolutorio, pues, como se afirmó en las consideraciones, "(...) no toda separación del programa obligacional por parte del deudor habilita a su contraparte para ejercer la mencionada facultad enderezada a que se decrete la extinción del contrato". La Corte procedió a señalar que el incumplimiento tiene como consecuencia no satisfacer el interés del acreedor, por lo que se debe distinguir entre incumplimiento total y definitivo, cumplimiento defectuoso, cumplimiento parcial o retardo (arts. 1613 y 1614 del CC). Por lo tanto, se puede calificar como esencial por insatisfacción del interés contractual, para lo que deben valorarse las circunstancias concretas pertinentes, y así medir la insatisfacción de tal interés del acreedor.

Así dijo la Corte en alguno de sus apartes:

\begin{abstract}
Sin embargo no toda separación por parte del deudor respecto del "programa obligacional" previamente establecido, permite poner en funcionamiento los mecanismos encaminados a extinguir la relación que une al obligado con el acreedor particularmente la resolución contractual-, toda vez que, en ciertas ocasiones, retrasos en el cumplimiento o cumplimientos parciales, que en principio podrían dar lugar a la resolución contractual, no se consideran de entidad suficiente como para justificar tan radical determinación, en cuanto se podrían producir con ello situaciones inequitativas, facilitar ejercicios abusivos o contrarios a la buena fe de la señalada facultad resolutoria, además de afectarse el principio de conservación del contrato.

En el contexto que se ha precisado anteriormente, la doctrina y la jurisprudencia han considerado que en esta materia resulta pertinente distinguir, entonces, si la obligación insatisfecha es una obligación principal o simplemente accesoria, o también si el incumplimiento es definitivo o apenas parcial o transitorio, y, en todo caso, analizar la trascendencia, importancia o gravedad del incumplimiento, determinadas tales circunstancias, entre otros criterios, por lo que las partes hayan convenido, por la afectación que se haya presentado en el interés del acreedor en el mantenimiento de la relación, por la frustración del fin práctico perseguido con el contrato -en la que se incluye la inobservancia de un término esencial-, o, en fin, por el impacto que se haya podido generar en la economía del contrato ${ }^{62}$.
\end{abstract}

De esta forma, precisó que el cumplimiento tardío puede ser considerado como esencial. Por ello, cabe el ejercicio de la acción resolutoria si es que, con posterioridad a una cierta oportunidad, el cumplimiento se vuelve inútil al acreedor, y si su interés en el derecho de crédito ha sido definitivamente lesionado o genera frustración del fin práctico perseguido por las partes en el contrato. Según esto, concluyó que el incumplimiento no podía ser calificado como esencial y, por tanto, no era resolutorio.

\title{
La noción unitaria de incumplimiento
}

Como ya se indicó, el cumplimiento de la obligación suele entenderse como la ejecución de la prestación debida, conforme con lo pactado por las partes, o bien lo establecido por la ley o por el juez, lo cual tiene como soporte legal el artículo 1613 del Código Civil, según el cual "el pago es la prestación de lo que se debe"63. A su vez, incumplimiento es la situación en la que el deudor inobserva la prestación debida al acreedor (ya sea por retardo o cumplimiento imperfecto), lo cual da lugar a las acciones correspondientes al acreedor ${ }^{64}$. En este contexto, puede entenderse que, como también se anotó anteriormente, es la manera en que se ha entendido a la obligación. Prestación es el comportamiento o conducta que el deudor debe realizar a favor del acreedor ${ }^{65}$.

Por el contrario, según la concepción asumida en este artículo, el incumplimiento se puede concebir como un hecho amplio y objetivo que produce la insatisfacción del interés del acreedor. Es posible afirmar de manera lógica que - partiendo del concepto realista de contrato ya aludida-, para comprender los problemas de cumplimiento e incumplimiento del contrato, estos deben ser asumidos como asuntos de satisfacción e insatisfacción del mencionado interés contractual. De este modo, el énfasis no ha de estar en la inejecución 
de la obligación, sino en la vinculación contractual, concepto que resulta más amplio, y que permite expresar las particularidades de las obligaciones surgidas del contrato, del mismo modo que se concibe en el moderno derecho de contratos ${ }^{66}$.

De acuerdo con este modelo, el deudor se obliga a realizar el contrato al garantizar la satisfacción del interés del acreedor. El deudor se obliga a cumplir el contrato y, si el deudor incumple en términos (que en el primer supuesto el acreedor satisface su interés y en el segundo su interés queda insatisfecho), activa los remedios al incumplimiento del acreedor. De esta forma, se ha de dar respuesta al siguiente interrogante: ¿cómo definir el interés contractual del acreedor? Esta pregunta y, más precisamente su respuesta, fuerza a examinar la concepción realista del contrato y la idea del propósito práctico del acreedor como elemento configurador de su contenido, del incumplimiento, y también de los remedios. No ha de olvidarse que se asume que los problemas de incumplimiento son problemas de insatisfacción del interés del acreedor; entonces, para avanzar, se ha de explicar cómo llegar a esta idea del interés del acreedor.

Como bien puede advertirse, en la concepción sostenida se desplaza la atención que se ha puesto a la prestación, hacia la satisfacción de los intereses del acreedor. Por lo tanto, permite construir un concepto unitario de incumplimiento que comprende tanto la no ejecución de las prestaciones, como también el cumplimiento tardío y el defectuoso ${ }^{67}$.

Esta concepción, resulta similar a la que se asume en el Common Law. En este sistema se considera que todos los contratos constituyen una promesa y van acompañados de una garantía, de manera que si el deudor incumple su promesa, es responsable por incumplimiento - sin que sea necesario separar las causas que lo generan, al distinguir entre imposibilidad, mora e incumplimiento positivo del contrato; y tampoco sea relevante establecer que el contrato se haya cumplido de manera tardía, o defectuosa, puesto que si no se cumplió con el resultado prometido, significa que no se observó la garantía, de lo cual resulta un incumplimiento- ${ }^{68}$. En este sistema, como consecuencia de haberse construido un concepto unitario de incumplimiento, se ha estructurado un sistema armónico de remedios. Estos aplican con cualquier contrato y a todo tipo de incumplimiento, aunque en ocasiones se reserve alguno de dichos remedios, como es la resolución, a que el incumplimiento sea esencial ${ }^{69}$.

Así entonces, los efectos que produzca el incumplimiento dependen de los efectos producidos en el interés contractual. Estos efectos son los que se denominan remedios, y tienen por objeto común permitir que el acreedor pueda lograr satisfacer sus intereses contractuales, a pesar del incumplimiento. Cada uno de los remedios tiene su propio supuesto de hecho o condiciones de procedencia y, así mismo, la opción entre uno $\mathrm{u}$ otro pertenece al acreedor ${ }^{70}$.

En definitiva, siguiendo lo planteado ya anteriormente por Vidal Olivares, puede asumirse que el incumplimiento es un hecho amplio, toda vez que para constatarlo basta con verificar la ausencia de coincidencia entre lo prometido por el deudor — denominado como el objeto ideal—, y lo ejecutado por el deudor de manera efectiva -el objeto real-, de manera que la consecuencia es obvia: cualquier desviación del objeto ideal implica el incumplimiento del deudor. De esta forma, el deudor no incumple una o más obligaciones aisladas, sino el contrato completo, y resulta indiferente la clase de obligación incumplida ${ }^{71}$.

Además de ser un hecho amplio, el incumplimiento es objetivo, puesto que no requiere la causa de la valoración de la conducta del deudor, o si se originó o no en un caso fortuito; sólo se centra en valorar que el deudor no cumplió lo prometido y, como consecuencia de ello, se produjo la insatisfacción del acreedor. Incluso, el incumplimiento originado en el caso fortuito permite al acreedor acudir a alguno de los remedios ${ }^{72}$.

Ahora bien, en lo que atañe al Derecho Privado colombiano, es posible elaborar una propuesta de relectura de algunas normas del Código Civil, para así poder afirmar que en él también subyace una concepción de incumplimiento objetiva y amplia (que permite articular los remedios que han sido otorgados al acreedor insatisfecho), y que subsume tanto la no ejecución de la obligación, como el cumplimiento tardío y defectuoso, comprendiéndose el supuesto de vicios ocultos ${ }^{73}$. Esta propuesta se basa en el concepto de pago, entendido 
"como la prestación de lo que se debe", que se encuentra consagrado en el artículo 1626 del Código Civil. A su vez, este debe ser efectuado "al tenor de la obligación”, según lo indica el principio de la identidad del pago. Como consecuencia, el acreedor no puede ser compelido a recibir una cosa diferente a la debida, ni siquiera con el pretexto de que esta sea de igual o mayor valor que la primera, conforme lo establece el artículo 1627 del Código Civil. De esta forma, la obligación debe ser ejecutada de la forma convenida, para que con ello el acreedor resulte satisfecho al alcanzar los intereses perseguidos ${ }^{74}$.

Sobre estas normas, es posible encontrar apoyo para concebir al incumplimiento como la no realización de la prestación debida, lo que abarca cualquier desviación del programa contractual convenido, y comprende el no cumplimiento, el cumplimiento defectuoso, y también el tardío. Esta clasificación, además, se encuentra admitida en las normas sobre el contenido de la indemnización de perjuicios por incumplimiento ${ }^{75}$. Cabe agregar que esta noción objetiva de incumplimiento no tiene en cuenta la culpa, o dolo, del deudor como requisito de procedencia de las acciones respectivas, salvo para el caso de la indemnización de perjuicios ${ }^{76}$. Esto permite demostrar que las normas de pago deben ser leídas de forma conjunta con las de incumplimiento y sus efectos ${ }^{77}$.

Si el pago no se efectúa según el tenor de la obligación, hay incumplimiento, y este producirá sus efectos. Es suficiente la discordancia entre el objeto ideal y el real para afirmar que el deudor ha incumplido, lo cual no solo incluye la ejecución de la actividad preestablecida en la obligación, sino también toda aquella actividad que sea necesaria para alcanzar el resultado en ella previsto — si se parte por insistir que la relación obligatoria no solo se entiende como la prestación o deber de conducta a realizar a favor del otro, sino como el cauce para la satisfacción de los intereses del acreedor ${ }^{78}$.

De forma similar, Diez Picazo indica que las relaciones obligatorias son instrumentos de cooperación social, orientados a conseguir el intercambio de bienes y servicios entre las personas. De ello se infiere que en toda obligación se encuentran previstos idealmente unos comportamientos, cuya finalidad es determinar la satisfacción y obtención de determinados intereses del acreedor, lo cual implica que se constituyan como un compromiso del deudor. Así, en su dinámica, la relación obligatoria puede desembocar, bien sea en unos hechos que coincidan con el programa primitivo surgido entre las partes, o se desvíen de él. De esta manera, cumplimiento e incumplimiento son las dos alternativas en que puede desembocar dicho vehículo dinámico: cumplimiento, si los actos se ajustan al programa contractual; o incumplimiento, si se desvían de él ${ }^{79}$. De esta forma, para que el pago sea regular y produzca efectos liberatorios, es necesario que el deber de prestación aparezca perfectamente cumplido, y el interés del acreedor satisfecho, lo cual exige un juicio que confronte el programa de prestación prometido y el efectivamente realizado ${ }^{80}$.

\section{Conclusiones}

Como conclusiones de lo anteriormente expuesto, puede sostenerse que el Código Civil colombiano no contiene una definición de incumplimiento, y tampoco de una disciplina de este. No obstante, a partir de las normas del pago del Código, y siguiendo el modelo del nuevo derecho de contratos, en especial el de la CISG, es posible ofrecer un concepto amplio y objetivo de incumplimiento. Amplio, al comprender toda hipótesis de realización de la prestación debida que no se conforme con el contrato, y al absorber incluso otras figuras especialmente regladas, como los vicios redhibitorios, la imposibilidad sobrevenida, e incluso el error. Objetivo, porque lo que importa es constatar la disconformidad entre lo pactado y lo ejecutado por el deudor, sin que sea relevante su causa, y sin importar que esté radicada en un caso fortuito o de fuerza mayor.

El incumplimiento, por regla general, es imputable al deudor; cuando no lo es, también se afirma su existencia, no obstante estar pendiente de la respuesta en torno a sus efectos o a los remedios de que dispone el acreedor. 
En esta definición, el propósito práctico del acreedor juega un rol esencial, dado que su consideración permitirá determinar si hay o no incumplimiento, en la medida que se halle incorporado al contrato, pues lo que resulta importante es que el deudor ejecute la prestación, y que esta sea idónea para que el acreedor realice o alcance su propósito práctico. De no ser el caso, se produce la insatisfacción del interés del acreedor $y$, por consiguiente, hay incumplimiento.

Así entonces, a partir de esta concepción, que es susceptible de ser construida en el Derecho colombiano, se pueden sentar las bases para estructurar un sistema armónico de remedios de los cuales dispone el acreedor, de manera que al emplearlos pueda solucionar de alguna forma la insatisfacción producida por el incumplimiento del deudor.

\section{Referencias}

Alejandro Guzmán Brito, La doctrina de la 'consideration' en Blackstone y su relación con la 'causa' del 'ius commune', Revista de Estudios Historico-Jurídicos, n. ${ }^{\circ} 25,375-406$ (2003). https://doi.org/10.4067/S0716-5455200300 2500010

Alejandro M. Garro \& Alberto L. Zuppi, Compraventa Internacional de Mercaderías. La Convención de Viena de 1980 (2. ed., Abeledo Perrot, 2012).

Álvaro Rodrigo Vidal Olivares, Cumplimiento e incumplimiento contractual en el Código Civil. Una perspectiva más realista, 34 Revista Chilena de Derecho, n. ${ }^{\circ}$ 1, 41-59 (2007). https://doi.org/10.4067/S0718-3437200700010 0004

Álvaro Rodrigo Vidal Olivares, Efectos particulares de la falta de conformidad de las mercaderías en la compraventa internacional de mercaderías, Revista de Derecho de la Pontificia Universidad Católica de Valparaíso, n. ${ }^{\circ} 25$, 559-593 (2005). http://www.rdpucv.cl/index.php/rderecho/article/viewArticle/608

Álvaro Rodrigo Vidal Olivares, El incumplimiento contractual y los remedios de que dispone el acreedor en la compraventa internacional, 33 Revista Chilena de Derecho, n. ${ }^{\circ} 3$, 439-477 (2006). https://doi.org/10.4067/S0718-343720 06000300002

Álvaro Rodrigo Vidal Olivares, La construcción de la regla contractual en el Derecho Civil de los contratos, Revista de Derecho de la Universidad Católica de Valparaíso, n. ${ }^{\circ}$ 21, 209-227 (2000). http://www.rdpucv.cl/index.php/r derecho/article/viewArticle/464

Álvaro Rodrigo Vidal Olivares, La función integradora de los principios generales en la compraventa internacional de mercaderias y los principios de la UNIDROIT sobre contratos comerciales internacionales, 56 Anuario de Derecho Civil, n. ${ }^{\circ}$ 3, 993-1041 (2003). https://dialnet.unirioja.es/descarga/articulo/802656.pdf

Álvaro Rodrigo Vidal Olivares, La noción de incumplimiento esencial en el código civil, Revista de Derecho de la Pontificia Universidad Católica de Valparaíso, n. ${ }^{\circ} 32$, 221-258 (2009). https://doi.org/10.4067/S0718-68512 009000100006

Álvaro Vidal Olivares \& Jorge Oviedo Albán, Protección del comprador por defectos materiales de la cosa vendida. Desde la fragmentación a un régimen unitario, 67 Vniversitas, n. ${ }^{\circ} 136,1-21$ (2018).

Álvaro Vidal Olivares, Cambio deparadigma en el incumplimiento, en Derecho de los contratos. Formación. Contenido. Incumplimiento y remedios del acreedor, 133-168 (Iñigo de la Maza Gazmuri \& Álvaro Vidal Olivares ed., Universidad Sergio Arboleda, 2017).

Álvaro Vidal Olivares, El incumplimiento de obligaciones con objeto fungible y los remedios del acreedor afectado. Una relectura de las disposiciones del "Código Civil" sobre incumplimiento, en El Código Civil de Chile (1855-2005) Trabajos expuestos en el congreso internacional celebrado para conmemorar su promulgación (Santiago, 2-6 de octubre de 2005), 495-550 (Alejandro Guzmán Brito ed., 2. edición, Legal Publishing, 2009).

Álvaro Vidal Olivares, Incumplimiento contractual y pretensión de cumplimiento específico en los Principios Latinoamericanos de Derecho de contratos (PLDC), en El derecho común europeo de la compraventa y la modernización del derecho de contratos, 745-767 (Antoni Vaquer Aloy, Esteve Bosch Capdevila \& María Paz Sánchez González eds., Atelier, 2015). 
Álvaro Vidal Olivares, La noción de incumplimiento. Una mirada unitaria desde la idea de la vinculación contractual garantía, en Estudios de derecho de contratos en homenaje a Antonio Manuel Morales Moreno, 447-474 (Álvaro Vidal Olivares \& Gonzalo Severin Fuster eds., Thomson Reuters, 2018).

Álvaro Vidal Olivares, La protección del comprador. Régimen de la Convención de Viena y su contraste con el Código Civil (Ediciones Universitarias de Valparaíso, 2006).

Ángel Carrasco Perera, Derecho de contratos (2. ${ }^{\mathrm{a}}$ ed., Thomson Reuters, 2017).

Antoni Vaquer Aloy, La armonización del Derecho de obligaciones y contratos (Astrea \& Universidad Sergio Arboleda, 2017).

Antonio Cabanillas Sánchez, Artículo 25, en La compraventa internacional de mercaderías. Comentario de la convención de Viena, 212 (Luis Díez-Picazo \& Ponce de León eds., Civitas, 1998).

Antonio Manuel Morales Moreno, ¿Es posible construir un sistema precontractual de remedios? Reflexiones sobre la Propuesta de modernización del Derecho de obligaciones y contratos en el marco del Derecho europeo, en Derecho Privado europeo y modernización del Derecho contractual en España, 400-422 (Klaus Jochen Albiez Dohrmann, María Luisa Palazón Garrido \& María del Mar Méndez Serrano ed., Atelier, 2011).

Antonio Manuel Morales Moreno, Artículo 35, en La compraventa internacional de mercaderías. Comentario de la Convención de Viena, 286-312 (Luis Diez-Picazo y Ponce de León eds., Civitas, 1998).

Antonio Manuel Morales Moreno, Claves de la modernización del Derecho de contratos (Ibañez \& Centro de Estudios de Derecho Comparado, 2016).

Antonio Manuel Morales Moreno, El 'propósito práctico' y la idea de negocio jurídico en Federico de Castro (Notas en torno a la significación de la utilidad de la cosa en los negocios de tráfico), 36 Anuario de Derecho Civil, n. ${ }^{\circ} 4,1529-1546$ (1983). https://dialnet.unirioja.es/descarga/articulo/46607.pdf

Antonio Manuel Morales Moreno, Evolución del concepto de obligación en el derecho español, en La modernización del Derecho de obligaciones, 17-54 (Antonio Manuel Morales Moreno, Thomson Civitas, 2006).

Antonio Manuel Morales Moreno, La conformidad de la cosa vendida según la Directiva 1999/44/CE, en La modernización del Derecho de obligaciones, 161-188 (Antonio Manuel Morales Moreno ed., Thomson Civitas, 2006).

Antonio Manuel Morales Moreno, La noción unitaria de incumplimiento e la Propuesta de Modernización del Código Civil, en Estudios sobre incumplimiento y resolución, 23-94 (Isabel González Pacanowsca \& Carmen Leonor García Pérez ed., Thomson Reuters Aranzadi, 2014).

Antonio Manuel Morales Moreno, Los Principios latinoamericanos de Derecho de los contratos. Un debate abierto sobre las grandes cuestiones jurídicas de la contratación, 67 Anuario de Derecho Civil, n. ${ }^{\circ}$ 1, 227-254 (2014). https://w ww.boe.es/publicaciones/anuarios_derecho/abrir_pdf.php?id=ANU-C-2014-10022700254

Antonio Vodanovic, Derecho Civil. Tratado de las obligaciones, basado en las explicaciones de los profesores de la Universidad de Chile Arturo Alessandri Rodríguez y Manuel Somarriva Undurraga (Editorial Jurídica de Chile, 2004).

Bénédicte Fauvarque-Cosson, Juliette Gest \& François Ancel, The Process of Elaboration of the Reform of the Law of Contract, en The Code Napoleón Rewritten. French Contract Law after the 2016 Reforms, 17-26 (John Cartwright, Simon Whittaker eds., 2017).

Benjamin J. Leisinger, Fundamental Breach Considering Non-Conformity of the Goods (Sellier European Law Series, 2007).

Carlos Pizarro Wilson (coord.), El derecho de los contratos en Latinoamérica. Bases para unos principios de Derecho de los contratos (Universidad del Rosario \& Universidad Externado de Colombia, 2012).

Carlos Pizarro Wilson, Hacia un sistema de remedios al incumplimiento contractual, en Estudios de Derecho Civil III, Jornadas nacionales de Derecho Civil Valparaíso 2007, 395-402 (Alejandro Guzmán Brito ed., Legal Publishing, 2008).

CISG-AC Opinion n.. 5, The buyer's right to avoid the contract in case of non-conforming goods or documents 7 May 2005, Badenweiler (Germany). Rapporteur: Professor Dr. Ingeborg Schwenzer, LL.M., Professor of Private Law, University of Basel. http://www.cisgac.com. 
Claudia Mejías Alonzo, El incumplimiento contractual y sus modalidades, en Estudios de Derecho Civil III, 459-478 (Alejandro Guzmán Brito ed., Legal Publishing, 2008).

Claudia Mejías Alonzo, El incumplimiento resolutorio en el Código Civil (Pontificia Universidad Católica de Valparaíso, Legal Publishing, 2011).

Código Civil Colombiano [CCC]. Ley 57 de 1887. 15 de abril de 1887 (Colombia).

Comisión de las Naciones Unidas para el Derecho Mercantil Internacional, Convención de las Naciones Unidas sobre los Contratos de Compraventa Internacional de Mercaderias, Naciones Unidas (2011).

Comisión Europea, Propuesta de Reglamento del Parlamento Europeo y del Consejo relativo a una normativa común de compraventa europea (2011). https://eur-lex.europa.eu/legal-content/ES/TXT/PDF/?uri=CELEX:52011PC $0635 \&$ from $=\mathrm{EN}$

Corte Suprema de Justicia, Sala de Casación Civil, Ref.: 41001-3103-004-1996-09616-01 (M. P. Arturo Solarte Rodríguez; 18 de diciembre de 2009).

Decreto 410 de 1971. Por el cual se expide el Código de Comercio. 16 de junio de 1971. D.O. No. 33339.

Enrique Barros Bourie, Finalidad y alcance de las acciones y los remedios contractuales, en Estudios de Derecho Civil III, Jornadas nacionales de Derecho Civil Valparaíso 2007, 403-428 (Alejandro Guzmán Brito ed., Legal Publishing, 2008).

Fabián Elorriaga de Bonis, Las dificultades de los remedios por incumplimiento contractual en la experiencia chilena, en Nuevos horizontes del derecho privado, 385-419 (Alexis Mondaca Miranda \& Cristián Aedo Barrena coords., Librotecnia, 2013).

Fabricio Mantilla Espinosa, La ejecución forzosa en la reforma del Código Civil francés, en Cumplimiento específico y ejecución forzada del contrato. De lo sustantivo a lo procesal, 85-107 (Álvaro Vidal Olivares \& Rodrigo Momberg Uribe, Pontificia Universidad Católica de Valparaíso, 2018).

Federico de Castro y Bravo, El negocio jurídico (Instituto Nacional de Estudios Jurídicos, 1971).

Fernando Fueyo Laneri, Cumplimiento e incumplimiento de las obligaciones (3. ${ }^{a}$ ed., Gonzalo Figueroa Yañez ed., Editorial Jurídica de Chile, 2004).

Fernando Pantaleón Prieto, Las nuevas bases de la responsabilidad contractual, Anuario de Derecho Civil, n. ${ }^{\circ} 46$, 1719-1746 (1993).https://www.boe.es/publicaciones/anuarios_derecho/abrir_pdf.php?id=ANU-C-1993-40 171901746

G. H. Treitel, The Law of Contract (11..ed., Thomson Sweet \& Maxwell, 2003).

Guillermo Ospina Fernández \& Eduardo Ospina Acosta, Teoría general del contrato y del negocio jurídico (7.a ed., Temis, 2016).

Harriet Schelhaas, Article 7.1.1., en Commentary on the Unidroit Principles of International Commercial Contracts (PICC), 829-833 (Stefan Vogenauer eds., 2.. ed., Oxford University Press, 2015).

Hélène Boucard, Le nouveau régime de l'inéxeecution contractuelle, en La réforme du droit des obligations en france, 153-170 (Reiner Schulze, Guillaume Wicker, Gerald Mäsch, Denis Mazeaud dirs., 2015).

Hernán Corral Talciani, Estudios sobre contratos y obligaciones (Ibañez \& Centro de Estudios de Derecho Comparado, 2016).

Hugo Cárdenas Villarreal \& Ricardo Reveco Urzúa, Remedios contractuales. Cláusulas, acciones y otros mecanismos de tutela del crédito (Thomson Reuters, 2018).

I Fernando Hinestrosa, Tratado de las obligaciones, Concepto, estructura, vicisitudes (3. ${ }^{a}$ ed., Universidad Externado de Colombia, 2007).

I René Abeliuk Manasevich, Las obligaciones (6 ${ }^{a}$ edición, Thomson Reuters, 2014).

II Fernando Hinestrosa, Tratado de las obligaciones II, De las fuentes de las obligaciones: el negocio jurídico (Universidad Externado de Colombia, 2015).

II Luis Diez-Picazo, Fundamentos del Derecho Civil patrimonial. Las relaciones obligatorias (6.a edición, Thomson Civitas, 2008).

II René Abeliuk Manasevich, Las obligaciones (6.a edición, Thomson Reuters, 2014). 
Ingeborg Schwenzer, Pascal Hachem \& Christopher Kee, Global Sales and Contract Law (Oxford University Press, 2012).

Iñigo De la Maza Gazmuri \& Álvaro Vidal Olivares, La modernización del derecho de contratos (Ibañez \& Centro de Estudios de Derecho Comparado, 2019).

Iñigo de la Maza Gazmuri, El régimen de los cumplimientos defectuosos en la compraventa, 39 Revista Chilena de Derecho, n. ${ }^{0}$ 3, 629-663 (2012). https://doi.org/10.4067/S0718-34372012000300003

Iñigo De la Maza, \& Álvaro Vidal, El contenido: una primera aproximación, en Los Principios Latinoamericanos de Derecho de los Contratos. Texto, presentación y contenidos fundamentales, 25-75 (Iñigo de la Maza, Carlos Pizarro \& Álvaro Vidal, BOE, Madrid, 2017).

Jaime Alcalde Silva, La causa de la relación obligatoria, en Estudios de Derecho Civil III, Jornadas nacionales de Derecho Civil Valparaíso 2007, 339-394 (Alejandro Guzmán Brito ed., Legal Publishing, 2008).

Jan Kleinheisterkamp, Los Principios Unidroit en la interpretación del Derecho nacional por tribunales estatales, en Principios de Derecho contractual europeo y Principios de Unidrot sobre contratos comerciales internacionales, 176-187 (María Pilar Ferrer Vandrell \& Anselmo Martínez Cañellas dirs., Dykinson, 2009).

Javier Lete Achirica, La transposición de la Directiva 1999/44 en el Derecho español mediante la Ley de 10 dejulio de 2003 de garantias en la venta de bienes de consumo, en Garantías en la venta de bienes de consumo. Les garanties dans la vente de biens de consommation, 195-225 (Javier Lete Achirica, Universidade de Santiago de Compostela, 2004).

Jens Kleinschmidt, Non-performance and remedies in general, en Commentaries on European Contract Laws, 1074-1184 (Nils Jansen \& Reinhard Zimmermann, Oxford University Press, 2018).

John Cartwright, Contract Law. An Introduction to the English Law of Contract for the Civil Lawyer (3.. ed., Hart Publishing, 2016).

Jorge Baraona Gónzalez, El retraso en el cumplimiento de las obligaciones (Dykinson, 1998).

Jorge Cubides Camacho, Obligaciones (8. ${ }^{a}$ ed., Pontificia Universidad Javeriana \& Ibañez, 2017).

Jorge López Santa María \& Fabián Elorriaga de Bonis, Los contratos, parte general (6. ${ }^{a}$ ed., Thomson Reuters, 2017).

Jorge Oviedo Albán, La falta de conformidad como alternativa a las problemáticas de los vicios ocultos y una propuestapara el derecho colombiano, Anuario de Derecho Privado, n. ${ }^{\circ}$ 1, 109-152 (2019). https://doi.org/10.15425/2017.199

Jorge Oviedo Albán, La garantía por vicios ocultos en la compraventa (Universidad de La Sabana \& Temis, 2015).

José Armando Bonivento Jiménez, Obligaciones (Legis, 2017).

Juan Pablo Pérez Velásquez, El proceso de modernización del Derecho contractual europeo (Dykinson, 2013).

Juan Pablo Pérez Velásquez, La indemnización de daños y perjuicios por incumplimiento del contrato en los Principios de Derecho contractual europeo (Boletín Oficial del Estado, 2016).

Konrad Zweigert \& Heinz Kötz, An Introduction to Comparative Law (3.. ed., Tony Weir trad., Oxford University Press, 1996).

Los Principios Latinoamericanos de Derecho de los Contratos (PLDC), disponible en https://www.boe.es/biblioteca juridica/abrir_pdf.php?id=PUB-PR-2017-44

Luis Claro Solar, Explicaciones de Derecho Civil chileno y comparado (Imprenta Nascimento, 1936.

Luis Díez-Picazo, El contenido de la relación obligatoria, 17 Anuario de Derecho Civil, n. ${ }^{\circ}$ 2, 349-366 (1964).

Luis Díez-Picazo, Encarna Roca Trías \& Antonio Manuel Morales Moreno, Los principios del derecho europeo de contratos (Civitas, 2002).

María Amalia Blandino Garrido, El incumplimiento del contrato, en El derecho común europeo de la compraventa y la modernización del derecho de contratos, 337-353 (Antoni Vaquer Aloy, Esteve Bosch Capdevila \& María Paz Sánchez González eds., Atelier, 2015).

María del Pilar Perales Viscasillas, Aplicación jurisprudencial de los Principios de Derecho contractual europeo, en Derecho privado europeo: estado actual y perspectivas de futuro. Jornadas en la Universidad Autónoma de Madrid, 13 y 14 de diciembre de 2007, 453-500 (María del Rosario Díaz Romero et. al., coords., Thomson Civitas, 2008). 
María Luisa Palazón Garrido, Los remedios frente al incumplimiento en el Derecho comparado (Thomson Reuters, 2014).

María Sara Rodríguez Pinto, Incumplimiento y exoneración de responsabilidad en los contratos de prestación de servicios. Los lineamientos de la responsabilidad estricta del proveedor, en Estudios de Derecho Civil III, Jornadas nacionales de Derecho Civil Valparaíso 2007, 503-517 (Alejandro Guzmán Brito ed., Legal Publishing, 2008).

Mario E. Clemente Meoro, La facultad de resolver los contratos por incumplimiento (Tirant lo Blanch, 1999).

Michael Bridge, The International Sale of Goods (4.. edition, Oxford University Press, 2017).

Nieves Fenoy Picón, El sistema de protección del comprador (Cuadernos de Derecho Registral, 2006).

Ole Lando, \& Hugh Beale, Principios de derecho contractual europeo: Partes I y II (Consejo General del Notariado, 2003).

Olivier Deshayes, Thomas Genicon \& Yves Marie Laithier, Réforme du droit des contrats, du régime général et de la preuve des obligations (2.. ed., LexisNexis, 2018).

Patrick Selim Atiyah, An Introduction to the Law of Contract (5.. edition, Oxford University Press, 1995).

Ramón Meza Barros, Manual de Derecho Civil (9.. ed., Editorial Jurídica de Chile, 2002).

Reinhard Zimmermann, Derecho Privado europeo (Antoni Vaquer Aloy (trad.) Astrea \& Universidad Sergio Arboleda, 2017).

Ricardo Uribe Holguín, De las obligaciones y de los contratos en general (2. ${ }^{a}$ ed., Temis, 1982).

Robert Joseph Pothier, Traite des obligations (Chez Debure l'aîné, 1761).

Rodrigo Momberg \& Stefan Vogenauer (eds.), The Future of Contract Law in Latin America. The Principles of Latin American Contract Law (Hart Publlishing, Oxford, 2017).

Solène Rowan, Remedies for Breach of Contract. A Comparative Analysis of the Protection of Performance (Oxford University Press, 2012).

The Principles of European Contract Law 2002 (PECL) (parts I, II, and III), disponible en: https://www.jus.uio.no/ $\mathrm{lm}$ /eu.contract.principles.parts.1.to.3.2002/

Thomas Genicon, La résolution du contrat pour inexécution (Bibliothèque de Droit Privé, LGDJ, 2007).

Unidroit, Principios Unidroit sobre los contratos comerciales internacionales 2016 (International Institute for the Unification of Private Law, 2018).

Yves Laithier, Étude comparative des sanctions de l'inexécution du contrat (L.G.D.J., París, 2007).

\section{Notas}

* Artículo de investigación

1 Se advierte sobre este tema, haciendo referencia tanto a las normas del Código Civil chileno como del colombiano, en: Iñigo De la Maza Gazmuri \& Álvaro Vidal Olivares, La modernización del derecho de contratos, 131 (Ibañez \& Centro de Estudios de Derecho Comparado, 2019).

2 Así, por ejemplo: José Armando Bonivento Jiménez, Obligaciones, 267 (Legis, 2017); Jorge Cubides Camacho, Obligaciones, 288 (8. ${ }^{a}$ ed., Pontificia Universidad Javeriana \& Ibañez, 2017). Ricardo Uribe Holguín, De las obligaciones y de los contratos en general, 107 (2. ed., Temis, 1982). También en la doctrina chilena: Fernando Fueyo Laneri,

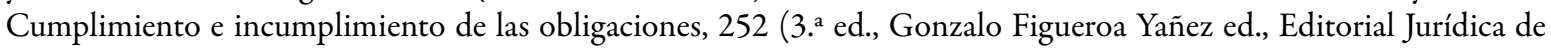
Chile, 2004).

3 En relación con este olvido, véase: Jorge Oviedo Albán, La garantía por vicios ocultos en la compraventa, 170 (Universidad de La Sabana \& Temis, 2015). De igual forma advertido en la doctrina chilena: Claudia Mejías Alonzo, El incumplimiento contractual y sus modalidades, en Estudios de Derecho Civil III, 476 a 477 (Alejandro Guzmán Brito ed., Legal Publishing, 2008) y Álvaro Rodrigo Vidal Olivares, Cumplimiento e incumplimiento contractual en el Código Civil. Una perspectiva más realista, 34 Revista Chilena de Derecho, n. ${ }^{\circ}$ 1, 52 (2007).

$4 \quad$ Ricardo Uribe Holguín, op. cit., 104.

5 Guillermo Ospina Fernández \& Eduardo Ospina Acosta, Teoría general del contrato y del negocio jurídico, 540 (7.a ed., Temis, 2016). En la doctrina chilena, Fabián Elorriaga ha hecho notar ya que en el Código Civil la falta de sistemática de los remedios frente al incumplimiento, dado que no existe un apartado especial donde se regulen de forma 
sistemática y ordenada los derechos del acreedor insatisfecho ante el incumplimiento del deudor, lo que se evidencia en que el incumplimiento contractual se encuentra regulado en las disposiciones "Del efecto de las obligaciones", entre los artículos 1545 a 1559 (equivalentes a los artículos 1602 a 1617 del Código Civil colombiano), en las que se advierte que no todas estas disposiciones se refieren al incumplimiento del contrato, y además faltan varios remedios frente al incumplimiento. Además, como también destaca el autor, el derecho a obtener la resolución del contrato y la ejecución forzada se encuentra en el artículo 1489 (equivalente al 1546 del Código Civil colombiano), en las disposiciones sobre obligaciones condicionales. Ver Fabián Elorriaga de Bonis, Las difcultades de los remedios por incumplimiento contractual en la experiencia chilena, en Nuevos horizontes del derecho privado, 385-419 (Alexis Mondaca Miranda \& Cristián Aedo Barrena coords., Librotecnia, 2013).

6 Cfr., en materia de compraventa: artículos 1870 y 1888 CC sobre defectos de cantidad; 1882 CC sobre retardo en la entrega de la cosa; 1914 a 1927 CC y 934 y 938 C.Co. sobre vicios ocultos en la compraventa; En cuanto a las reglas de arrendamiento de cosas: artículo 1984 CC sobre incumplimiento de la obligación del arrendador de entregar la cosa. Artículo 2217 CC sobre indemnización de perjuicios por la mala calidad del objeto en el comodato. Artículo 2228 CC sobre responsabilidad del mutuante por la mala calidad de la cosa. Artículo 973 C. Co., en el contrato de suministro de cosas. Este tema ha sido advertido recientemente en Jorge Oviedo Albán, La falta de conformidad como alternativa a las problemáticas de los vicios ocultos y una propuesta para el derecho colombiano, Anuario de Derecho Privado, n. ${ }^{\circ}$, 109-152 (2019) y en Álvaro Vidal Olivares \& Jorge Oviedo Albán, Protección del comprador por defectos materiales de la cosa vendida. Desde la fragmentación a un régimen unitario, 67 Vniversitas, n. ${ }^{\circ} 136,3-5$ (2018).

7 La reforma, que versa sobre Derecho de contratos, régimen general y de la prueba de las obligaciones, fue adoptada por la Ordenanza 2016 - 131 de 10 de febrero de 2016 y entró a regir el 1 de octubre de 2016. La ordenanza fue ratificada por ley 2018 - 287 de 20 de abril de 2018. En relación con el proceso que condujo a la adopción de la reforma, véase: Bénédicte Fauvarque-Cosson, Juliette Gest \& François Ancel, The Process of Elaboration of the Reform of the Law of Contract, en The Code Napoleón Rewritten. French Contract Law after the 2016 Reforms, 17-26 (John Cartwright, Simon Whittaker eds., 2017).

8 Los Principios Latinoamericanos de Derecho de Contratos corresponden a un proyecto elaborado a instancias de un grupo de profesores de varios países de América Latina, auspiciado por la "Fondation pour le droit continental". Sobre el particular: Iñigo De la Maza \& Álvaro Vidal, El contenido: una primera aproximación, en Los Principios Latinoamericanos de Derecho de los Contratos. Texto, presentación y contenidos fundamentales, 25-75 (Iñigo de la Maza, Carlos Pizarro \& Álvaro Vidal, BOE, Madrid, 2017); Antonio Manuel Morales Moreno, Los Principios latinoamericanos de Derecho de los contratos. Un debate abierto sobre las grandes cuestiones juridicas de la contratación, 67 Anuario de Derecho Civil, n. ${ }^{\circ}$ 1, 227-254 (2014); Rodrigo Momberg \& Stefan Vogenauer (eds.), The Future of Contract Law in Latin America. The Principles of Latin American Contract Law (Hart Publlishing, Oxford, 2017); Álvaro Vidal Olivares, Incumplimiento contractual y pretensión de cumplimiento especifico en los Principios Latinoamericanos de Derecho de contratos (PLDC), en El derecho común europeo de la compraventa y la modernización del derecho de contratos, 745-748 (Antoni Vaquer Aloy, Esteve Bosch Capdevila \& María Paz Sánchez González eds., Atelier, 2015). Para conocer el propósito y la génesis de los PLDC: Carlos Pizarro Wilson (coord.), El derecho de los contratos en Latinoamérica. Bases para unos principios de Derecho de los contratos (Universidad del Rosario \& Universidad Externado de Colombia, 2012).

9 Sobre la forma como estos instrumentos plasman la "corriente renovadora" del Derecho de contratos, véase: Antonio Manuel Morales Moreno, Claves de la modernización del Derecho de contratos, 36-38 (Ibañez \& Centro de Estudios de Derecho Comparado, 2016). De igual forma: Juan Pablo Pérez Velásquez, El proceso de modernización del Derecho contractual europeo, 89-151 (Dykinson, 2013).

10 En cuanto a esta posibilidad y la aplicación de los PCCI por parte de tribunales estatales, véase: Jan Kleinheisterkamp, Los Principios Unidroit en la interpretación del Derecho nacional por tribunales estatales, en Principios de Derecho contractual europeo y Principios de Unidrot sobre contratos comerciales internacionales, 176-187 (María Pilar Ferrer Vandrell \& Anselmo Martínez Cañellas dirs., Dykinson, 2009). Así también, en el caso español, en referencia a la aplicación de los PECL por los tribunales ya sea para sustentar o apoyar la interpretación de alguna institución jurídica no expresamente recogida en los códigos civil y mercantil, para confirmar principios o reglas contenidos en los códigos o en leyes especiales, además de conformar o apoyar la doctrina jurídica o integrar lagunas del Código Civil, véase: María del Pilar Perales Viscasillas, Aplicación jurisprudencial de los Principios de Derecho contractual europeo, en Derecho privado europeo: estado actual y perspectivas de futuro. Jornadas en la Universidad Autónoma de Madrid, 13 y 14 de diciembre de 2007, 453-500 (María del Rosario Díaz Romero et. al., coords., Thomson Civitas, 2008); Juan Pablo Pérez Velásquez, El proceso de modernización del Derecho contractual europeo, 173-191 (Dykinson, 2013).

11 Patrick Selim Atiyah, An Introduction to the Law of Contract, 416 (5.a edition, Oxford University Press, 1995); Jens Kleinschmidt, Non-performance and remedies in general, en Commentaries on European Contract Laws, 1083 (Nils Jansen \& Reinhard Zimmermann, Oxford University Press, 2018). John Cartwright, Contract Law. An Introduction to the English Law of Contract for the Civil Lawyer, 273 (3.a ed., Hart Publishing, 2016). Solène Rowan, Remedies for 
Breach of Contract. A Comparative Analysis of the Protection of Performance, 4 (Oxford University Press, 2012). Véase en cuanto al alcance de la palabra "remedies" en el Derecho anglosajón y una alusión a la inexactitud de su uso en la cultura jurídica francesa: Yves Laithier, Étude comparative des sanctions de l'inexécution du contrat, 9-11 (L.G.D.J., París, 2007). También se pronuncia críticamente Mantilla, al señalar que la palabra que debe emplearse en español es "sanction", entendida como la punición por el incumplimiento de una obligación. Fabricio Mantilla Espinosa, La ejecución forzosa en la reforma del Código Civil francés, en Cumplimiento específico y ejecución forzada del contrato. De lo sustantivo a lo procesal, 89, nt. 23 (Álvaro Vidal Olivares \& Rodrigo Momberg Uribe, Pontificia Universidad Católica de Valparaíso, 2018).

12 Ingeborg Schwenzer, Pascal Hachem \& Christopher Kee, Global Sales and Contract Law, 34 (Oxford University Press, 2012).

13 Antonio Manuel Morales Moreno, Claves de la modernización del Derecho de contratos, op. cit., 97.

14 Antonio Manuel Morales Moreno, ¿Es posible construir un sistema precontractual de remedios? Reflexiones sobre la Propuesta de modernización del Derecho de obligaciones y contratos en el marco del Derecho europeo, en Derecho Privado europeo y modernización del Derecho contractual en España, 402 (Klaus Jochen Albiez Dohrmann, María Luisa Palazón Garrido \& María del Mar Méndez Serrano ed., Atelier, 2011). De igual forma María Luisa Palazón Garrido, Los remedios frente al incumplimiento en el Derecho comparado, 16 (Thomson Reuters, 2014) y Vidal Olivares, quien se refiere a los remedios como “...los derechos o acciones de que dispone al acreedor afectado para la realización de su interés”. Álvaro Vidal Olivares, La protección del comprador. Régimen de la Convención de Viena y su contraste con el Código Civil, 30 (Ediciones Universitarias de Valparaíso, 2006); Álvaro Vidal Olivares, El incumplimiento de obligaciones con objeto fungible y los remedios del acreedor afectado. Una relectura de las disposiciones del "Código Civil" sobre incumplimiento, en El Código Civil de Chile (1855-2005) Trabajos expuestos en el congreso internacional celebrado para conmemorar su promulgación (Santiago, 2-6 de octubre de 2005), 510-520 (Alejandro Guzmán Brito ed., 2. a edición, Legal Publishing, 2009). Véase también: Carlos Pizarro Wilson, Hacia un sistema de remedios al incumplimiento contractual, en Estudios de Derecho Civil III, Jornadas nacionales de Derecho Civil Valparaíso 2007, 395-402 (Alejandro Guzmán Brito ed., Legal Publishing, 2008); Enrique Barros Bourie, Finalidad y alcance de las acciones y los remedios contractuales, en Estudios de Derecho Civil III, Jornadas nacionales de Derecho Civil Valparaíso 2007, 403-428 (Alejandro Guzmán Brito ed., Legal Publishing, 2008).

15 CISG, Parte tercera, capítulo II, sección III y capítulo III, sección III.

16 Ver Alejandro M. Garro \& Alberto L. Zuppi, Compraventa Internacional de Mercaderías. La Convención de Viena de 1980, 285-296 (2. a ed., Abeledo Perrot, 2012).

17 En efecto, el texto del artículo 3.2.4 PCCI, dispone: "(Remedios por incumplimiento) Una parte no puede anular el contrato a causa de error si los hechos en los que basa su pretensión le otorgan o le podrían haber otorgado remedios por incumplimiento". Unidroit, Principios Unidroit sobre los contratos comerciales internacionales 2016, 116 (International Institute for the Unification of Private Law, 2018).

18 Antonio Manuel Morales Moreno, Evolución del concepto de obligación en el derecho español, en La modernización del Derecho de obligaciones, 30-32 (Antonio Manuel Morales Moreno, Thomson Civitas, 2006); Ángel Carrasco Perera,

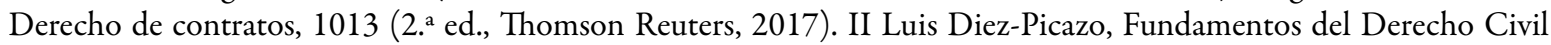
patrimonial. Las relaciones obligatorias, 803 (6.a edición, Thomson Civitas, 2008).

19 Álvaro Rodrigo Vidal Olivares, La noción de incumplimiento esencial en el código civil, Revista de Derecho de la Pontificia Universidad Católica de Valparaíso, n. ${ }^{\circ}$ 32, 233 (2009); Antonio Manuel Morales Moreno, op. cit., 90. Antonio Manuel Morales Moreno, La noción unitaria de incumplimiento e la Propuesta de Modernización del Código Civil, en Estudios sobre incumplimiento y resolución, 27 (Isabel González Pacanowsca \& Carmen Leonor García Pérez ed., Thomson Reuters Aranzadi, 2014). Nieves Fenoy Picón, El sistema de protección del comprador, 196-200 (Cuadernos de Derecho Registral, 2006); Kleinschmidt, op. cit., 1078 y 1081.

20 Véase Álvaro Rodrigo Vidal Olivares, La función integradora de los principios generales en la compraventa internacional de mercaderías y los principios de la UNIDROIT sobre contratos comerciales internacionales, 56 Anuario de Derecho Civil, n. 3 3, 993-1041 (2003).

21 Álvaro Rodrigo Vidal Olivares, La noción de incumplimiento esencial en el código civil, op.cit., 233 y 234.

22 Antonio Cabanillas Sánchez, Artículo 25, en La compraventa internacional de mercaderías. Comentario de la convención de Viena, 212 (Luis Díez-Picazo \& Ponce de León eds., Civitas, 1998); ver G. H. Treitel, The Law of Contract, $225-241$ (11.a ed., Thomson Sweet \& Maxwell, 2003).

23 Michael Bridge, The International Sale of Goods, 668 (4.a edition, Oxford University Press, 2017); Antonio Cabanillas Sánchez, op. cit., 215; Benjamin J. Leisinger, Fundamental Breach Considering Non-Conformity of the Goods, 38 (Sellier European Law Series, 2007); Álvaro Rodrigo Vidal Olivares, Efectos particulares de la falta de conformidad de las mercaderías en la compraventa internacional de mercaderias, Revista de Derecho de la Pontificia Universidad Católica de Valparaíso, n. ${ }^{\circ} 25,574$ (2005). Véase: CISG-AC Opinion n.. 5, The buyer's right to avoid the contract in case of non- 
conforming goods or documents 7 May 2005, Badenweiler (Germany). Rapporteur: Professor Dr. Ingeborg Schwenzer, LL.M., Professor of Private Law, University of Basel.

24 Álvaro Rodrigo Vidal Olivares, El incumplimiento contractual y los remedios de que dispone el acreedor en la compraventa internacional, 33 Revista Chilena de Derecho, n. ${ }^{\circ}$ 3, 468 (2006).

25 Íd., 451.

26 Íd.

27 artículo 45 y siguientes de la CISG

28 artículo 61 y siguientes de la CISG

29 Mario E. Clemente Meoro, La facultad de resolver los contratos por incumplimiento, 239-240 (Tirant lo Blanch, 1999).

30 artículo 45 y siguientes de la CISG

31 artículo 61 y siguientes de la CISG

32 establecidas en el artículo 35 y siguientes

33 en el artículo 7.1.1 de los PCCI

34 (artículos 7.2.1 a 7.2.5)

35 (artículos 7.3.1 a 7.3.7)

36 (artículos 7.4.1 a 7.4.13); Ver Nieves Fenoy Picón, op. cit., 191 a 207.

37 Harriet Schelhaas, Article 7.1.1., en Commentary on the Unidroit Principles of International Commercial Contracts (PICC), 830 (Stefan Vogenauer eds., 2.a ed., Oxford University Press, 2015).

38 Nieves Fenoy Picón, op. cit., 183 a 187 y 222.

39 El DCFR, al definir el "non-perfomance" no se refiere al contrato sino a la obligación; el artículo 1:101 (3) establece: "Non-performance of an obligation is any failure to perform the obligation, whether or not excused, and includes delayed performance and any other performance which is not in accordance with the terms regulating the obligation".

40 Ole Lando, \& Hugh Beale, Principios de derecho contractual europeo: Partes I y II, 163 (Consejo General del Notariado, 2003); Juan Pablo Pérez Velásquez, La indemnización de daños y perjuicios por incumplimiento del contrato en los Principios de Derecho contractual europeo, 43 (Boletín Oficial del Estado, 2016).

41 Antonio Manuel Morales Moreno, Evolución del concepto de obligación en el derecho español, op. cit., 26.

42 El grupo redactor de los PLDC decidió no utilizar el término "remedios" asumiendo que se trata de una voz ajena a la tradición de Derecho europeo continental y además, porque en el "common law" abarca no sólo el campo contractual y con ello se quiso evitar equívocos. Sobre este aspecto: Iñigo De la Maza \& Álvaro Vidal, op. cit., 51-55.

43 En efecto, como ya se ha anotado: "El incumplimiento de contrato es el reverso de su cumplimiento. De esta manera, se incumple el contrato cuando el deudor no realiza lo acordado o lo realiza imperfectamente, sea que se trate de un cumplimiento parcial, tardío, o que adolezca de alguna anomalía material o jurídica. Hay incumplimiento de contrato cuando el objeto real, lo ejecutado por el deudor, no coincide o no se conforma con el objeto ideal, lo pactado o acordado por las partes, entendido en el sentido explicado a propósito del contenido del contrato. Añadiéndose que la disposición transcrita, al conceptualizar los cumplimientos imperfectos, incorpora, aunque oblicuamente, el principio de la conformidad del cumplimiento y, además, recoge el principio según el cual el hecho del deudor comprende el de sus auxiliares o las personas que emplee para la realización del contrato, desde que integran su esfera de control. En los Principios, al igual que en los instrumentos de derecho uniforme, el Código Civil francés y las propuestas de reforma al Código Civil español, el incumplimiento constituye un hecho amplio y objetivo". Iñigo De la Maza \& Álvaro Vidal, op. cit., 51 y 52 .

44 Iñigo De la Maza \& Álvaro Vidal, op. cit., 52. El texto del artículo 90 es el siguiente: (1) La imposibilidad sobreviniente total y definitiva para cumplir una obligación contractual, causada por caso fortuito, extingue la obligación y libera al deudor. En tal caso, el acreedor puede optar por resolver el contrato o reclamar la cesión de los derechos y acciones que, en razón de la imposibilidad, el deudor detenta contra un tercero. (2) Si la imposibilidad es parcial o temporal, el acreedor puede suspender la contraprestación o reducirla en una proporción equivalente, salvo si, como consecuencia de la imposibilidad, se ve privado de aquello que podía sustancialmente esperar al tiempo de celebrarse el contrato. En este último supuesto rige la opción prevista en el punto (1)".

45 Iñigo De la Maza \& Álvaro Vidal, op. cit., 53 y 54.

46 Hélène Boucard, Le nouveau régime de l'inéxeecution contractuelle, en La réforme du droit des obligations en france, 156-157 (Reiner Schulze, Guillaume Wicker, Gerald Mäsch, Denis Mazeaud dirs., 2015).

47 Ya se ha destacado en la doctrina tanto francesa como hispanoparlante, que una de las grandes innovaciones de la reforma ha sido la sistematización de las sanciones por incumplimiento contractual superando de esta manera la regulación parcelada y desordenada contenida en el Code. Ver Fabricio Mantilla Espinosa, op. cit., 95. Olivier Deshayes, Thomas Genicon \& Yves Marie Laithier, Réforme du droit des contrats, du régime général et de la preuve des obligations, 534 (2.a ed., LexisNexis, 2018).

48 Luis Díez-Picazo, Encarna Roca Trías \& Antonio Manuel Morales Moreno, Los principios del derecho europeo de contratos, 317 (Civitas, 2002). Conviene destacar estas palabras de los autores quienes, sobre el particular, aunque 
refiriéndose a los PECL, pero también extrapolable a los demás demás instrumentos destacados, anotan: "Conforme a este artículo hay dos principios básicos a partir de los cuales se construye el sistema de responsabilidad contractual en los PECL. El primero es la unificación del concepto de incumplimiento, con la consiguiente equiparación jurídica de todas las manifestaciones que pueda tener el mismo. Conforme a los Principios, el incumplimiento consiste en la no ejecución de cualquier obligación derivada del contrato. El segundo es la articulación de un sistema unitario y armonizado de remedios para el caso del incumplimiento (...) Todos ellos integran lo que, en un sentido amplio, podríamos denominar el sistema de responsabilidad contractual; es decir, el conjunto de consecuencias jurídicas derivadas del incumplimiento, orientadas a satisfacer el interés del contratante insatisfecho. El sistema unitario de responsabilidad contractual plasmado en los PECL contrasta con la fragmentación presente en la mayoría de los ordenamientos continentales". Luis DíezPicazo, Encarna Roca Trías \& Antonio Manuel Morales Moreno, op. cit., 317. Téngase en cuenta que, siguiendo la línea trazada por los instrumentos internacionales ya descritos, la Propuesta de Reglamento del Parlamento Europeo y del Consejo relativo a una normativa común de compraventa europea (CESL), también se incluía en el artículo 87 una noción amplia, unitaria y de carácter neutro del incumplimiento. Ver María Amalia Blandino Garrido, El incumplimiento del contrato, en El derecho común europeo de la compraventa y la modernización del derecho de contratos, 337-353 (Antoni Vaquer Aloy, Esteve Bosch Capdevila \& María Paz Sánchez González eds., Atelier, 2015).

49 Thomas Genicon, La résolution du contrat pour inexécution, 206-207 (Bibliothèque de Droit Privé, LGDJ, 2007).

50 Como se ha destacado ya en Álvaro Rodrigo Vidal Olivares, La noción de incumplimiento esencial en el código civil, op.cit., 235.

51 Noción esta que, en el Código civil colombiano, se adopta en los arts. 1494 CC col.; 1438 CC chil. Sobre la noción de contrato adoptada por el Código de Bello, Hernán Corral Talciani, Estudios sobre contratos y obligaciones, 29-56 (Ibañez \& Centro de Estudios de Derecho Comparado, 2016). Es coincidente la apreciación de la doctrina de Colombia y Chile en criticar esta noción señalando que ella más que definir el contrato definió la obligación. Puede verse, entre otros: Jorge López Santa María \& Fabián Elorriaga de Bonis, Los contratos, parte general, 5 (6. a ed., Thomson Reuters, 2017); Jorge Cubides Camacho, op. cit., 252.

52 Es tradicional la concepción de obligación entendida como vínculo entre acreedor y deudor conforme al cual el primero puede exigir del segundo una prestación de dar, hacer o no hacer. Esta concepción comprende el concepto "crédito", asumido como la facultad del acreedor para exigir la conducta del deudor y la "deuda", que se entiende como la prestación o conducta que debe realizar el deudor. Ver, entre otros: I René Abeliuk Manasevich, Las obligaciones, 35 (6. ${ }^{\mathrm{a}}$ edición, Thomson Reuters, 2014). Luis Claro Solar, Explicaciones de Derecho Civil chileno y comparado, 5 (Imprenta Nascimento, 1936; I Fernando Hinestrosa, Tratado de las obligaciones, Concepto, estructura, vicisitudes, 55 (3..$^{a}$ ed., Universidad Externado de Colombia, 2007); Guillermo Ospina Fernández \& Eduardo Ospina Acosta, op. cit., 20; II Luis Diez-Picazo, Fundamentos del Derecho Civil patrimonial. Las relaciones obligatorias, op. cit., 116. Este concepto al parecer hunde sus raíces en algunos apartados de las Institutas de Justiniano y el Digesto, en los cuales se basó Pothier para definir a la obligación como el "vínculo de derecho que nos liga hacia otro a darle, hacer o dejar de hacer alguna cosa". En efecto, en su "Tratado de las obligaciones", el autor cita un apartado de las Institutas (3.XIII, pr.), según el cual: "Obligatio est iuris vinculum, quo necessitate adstringimur alicuius solvendae rei secundum nostrae civitatis iura" y en el Digesto (D. 44, 7, 3, Paul., 2 inst.): “Obligationum substantia non in eo consistit, ut aliquod corpus nostrum, aut servitutem nostram faciat, sed ut alium nobis obstringat ad dandum aliquid, vel faciendum, vel praestandum” y a partir de estos dos formula el concepto aludido. Robert Joseph Pothier, Traite des obligations, 3 (Chez Debure l'aîné, 1761).

53 Sobre la idea de obligación en los sistemas continentales y su reflejo en sus códigos civiles: Antonio Manuel Morales Moreno, op. cit., 81. Cabe destacar las palabras del autor quien sobre este particular indica: "La idea de obligación utilizada en los sistemas continentales (reflejada en sus Códigos civiles) adolece de un alto grado de generalización (que, en un momento histórico, fue necesario para construir el Derecho de obligaciones), y de una visión parcial del fenómeno de las relaciones obligatorias. Esta idea considera, prioritariamente, la conducta exigible al deudor; y está estrechamente relacionada con el concepto de derecho subjetivo. El derecho de crédito se ha venido caracterizando como el poder del acreedor sobre ciertas manifestaciones concretas de la conducta del deudor (conducta exigible al deudor; prestación). La modernización del Derecho de contratos está contribuyendo a revisar este enfoque parcial del fenómeno jurídico que subyace en la relación contractual”. Íd.

54 Álvaro Vidal Olivares, La noción de incumplimiento. Una mirada unitaria desde la idea de la vinculación contractual garantía, en Estudios de derecho de contratos en homenaje a Antonio Manuel Morales Moreno, 461 (Álvaro Vidal Olivares \& Gonzalo Severin Fuster eds., Thomson Reuters, 2018). Es por esto por lo que señala Morales Moreno que: "La expresión incumplimiento de un deber u obligación no es adecuada. Primero porque las garantías asumidas por un contratante frente al otro también le vinculan, y pueden dar lugar a incumplimientos que no resultan de la falta de ejecución de un deber de conducta, sino de que los hechos o resultados garantizados no son o no se producen como debiera ser conforme al contrato. Segundo, porque, además, si el incumplimiento se limita a los deberes de conducta puede aflorar inevitablemente, como ingrediente natural, el de la culpabilidad (la exigencia de responsabilidad sin culpa entra en la esfera de la garantía). La expresión más adecuada para indicar todos los elementos que se integran en el 
moderno concepto de incumplimiento es, 'incumplimiento del contrato'. En ella se incluye el de las obligaciones surgidas del mismo, pero no se limita a estas". Antonio Manuel Morales Moreno, La noción unitaria de incumplimiento e la Propuesta de Modernización del Código Civil, op. cit., 27.

55 Antonio Manuel Morales Moreno, Evolución del concepto de obligación en el derecho español, op. cit., 20. La noción se apoya en de "negocio jurídico" asumida por Federico de Castro y Bravo, conforme a la cual este es la declaración o acuerdo de voluntades con que los particulares se proponen conseguir un resultado. Federico de Castro y Bravo, El negocio jurídico, 34 (Instituto Nacional de Estudios Jurídicos, 1971). Sobre la doctrina del propósito práctico en la literatura jurídica chilena, véase: Álvaro Rodrigo Vidal Olivares, La construcción de la regla contractual en el Derecho Civil de los contratos, Revista de Derecho de la Universidad Católica de Valparaíso, n. 21, 209-227 (2000); María Sara Rodríguez Pinto, Incumplimiento y exoneración de responsabilidad en los contratos de prestación de servicios. Los lineamientos de la responsabilidad estricta del proveedor, en Estudios de Derecho Civil III, Jornadas nacionales de Derecho Civil Valparaíso 2007, 507 (Alejandro Guzmán Brito ed., Legal Publishing, 2008).

56 Antonio Manuel Morales Moreno, El 'propósito práctico' y la idea de negocio jurídico en Federico de Castro (Notas en torno a la significación de la utilidad de la cosa en los negocios de tráfico), 36 Anuario de Derecho Civil, n. ${ }^{\circ} 4,1529-1546$ (1983).

57 Antonio Manuel Morales Moreno, El 'propósito práctico' y la idea de negocio jurídico en Federico de Castro (Notas en torno a la significación de la utilidad de la cosa en los negocios de tráfico), op. cit., 1530, 1533, 1535 y 1537. El contrato “....representa para el acreedor una garantía de satisfacción de su interés contractual, quien contrata precisamente en consideración a esa satisfacción". Álvaro Rodrigo Vidal Olivares, El incumplimiento contractual y los remedios de que dispone el acreedor en la compraventa internacional, op. cit., 439; Antonio Manuel Morales Moreno, La conformidad de la cosa vendida según la Directiva 1999/44/CE, en La modernización del Derecho de obligaciones, 164-165 (Antonio Manuel Morales Moreno ed., Thomson Civitas, 2006); Javier Lete Achirica, La transposición de la Directiva 1999/44 en el Derecho español mediante la Ley de 10 de julio de 2003 de garantías en la venta de bienes de consumo, en Garantías en la venta de bienes de consumo. Les garanties dans la vente de biens de consommation, 209 (Javier Lete Achirica, Universidade de Santiago de Compostela, 2004). Álvaro Vidal Olivares, Cambio de paradigma en el incumplimiento, en Derecho de los contratos. Formación. Contenido. Incumplimiento y remedios del acreedor, 158 (Iñigo de la Maza Gazmuri \& Álvaro Vidal Olivares ed., Universidad Sergio Arboleda, 2017); Álvaro Rodrigo Vidal Olivares, Cumplimiento e incumplimiento contractual en el Código Civil. Una perspectiva más realista, op. cit., 49; Claudia Mejías Alonzo, op. cit., 477; Fernando Pantaleón Prieto, Las nuevas bases de la responsabilidad contractual, Anuario de Derecho Civil, n. ${ }^{\circ} 46,1719-1746$ (1993). Así, en el Derecho español Mario E. Clemente Meoro afirma que cabe la opción para el comprador entre las acciones edilicias y las de incumplimiento. En este sentido, dice el autor, los vicios ocultos, además de la existencia en la cosa de gravámenes, servidumbres o la pérdida de la posesión pacífica de ella, pueden considerarse supuestos de incumplimiento en sentido amplio. Mario E. Clemente Meoro, op. cit., 301-306.

58 Antonio Manuel Morales Moreno, Evolución del concepto de obligación en el derecho español, op. cit., 22. En este sentido ver también Álvaro Rodrigo Vidal Olivares, El incumplimiento contractual y los remedios de que dispone el acreedor en la compraventa internacional, op. cit., 450 y 452.

59 Alcalde Silva sostiene en la doctrina chilena que el artículo 1467 CC chil., equivalente al 1524 CC col., se refiere al motivo determinante de la voluntad contractual, a su razón impulsora, en suma, al propósito perseguido por las partes al celebrar el negocio. Añade el autor que la expresión motivos empleada por el legislador debe entenderse como aquello que mueve o tiene eficacia o virtud de mover; o bien la razón que mueve para algo, lo que extrapolado al contrato designaría a la finalidad última que las partes quieren alcanzar o satisfacer con el contrato. Jaime Alcalde Silva, La causa de la relación obligatoria, en Estudios de Derecho Civil III, Jornadas nacionales de Derecho Civil Valparaíso 2007, 368-369 (Alejandro Guzmán Brito ed., Legal Publishing, 2008). Sobre el respaldo histórico de esta forma de entender la expresión motivos del artículo 1467 CC chil 1524 col., véase: Alejandro Guzmán Brito, La doctrina de la 'consideration' en Blackstone y su relación con la 'causa' del 'ius commune', Revista de Estudios Historico-Jurídicos, n. ${ }^{\circ} 25,383$ (2003).

60 Antonio Manuel Morales Moreno, Evolución del concepto de obligación en el derecho español, op. cit., 29 a 33. Antoni Vaquer Aloy, La armonización del Derecho de obligaciones y contratos, 342-347 (Astrea \& Universidad Sergio Arboleda, 2017); Reinhard Zimmermann, Derecho Privado europeo, 121-125 (Antoni Vaquer Aloy (trad.) Astrea \& Universidad Sergio Arboleda, 2017).

61 Íd.

62 Corte Suprema de Justicia, Sala de Casación Civil, Ref.: 41001-3103-004-1996-09616-01 (M. P. Arturo Solarte Rodríguez; 18 de diciembre de 2009).

63 II René Abeliuk Manasevich, Las obligaciones, 715 (6. ${ }^{a}$ edición, Thomson Reuters, 2014); Guillermo Ospina Fernández \& Eduardo Ospina Acosta, op. cit., 316.

64 En esta perspectiva, el acreedor tiene un derecho subjetivo cuyo objeto consiste en la obtención de la prestación debida por el deudor. II Luis Diez-Picazo, Fundamentos del Derecho Civil patrimonial. Las relaciones obligatorias, op. cit., 116. También en el sentido de centrar el concepto de incumplimiento en la no ejecución de la prestación, Hinestrosa lo define así: "Incumplimiento del contrato quiere decir inejecución de obligación emanada de él, imputable al deudor y, 
en términos generales, atribuible a culpa suya”. II Fernando Hinestrosa, Tratado de las obligaciones II, De las fuentes de las obligaciones: el negocio jurídico, 871 (Universidad Externado de Colombia, 2015).

65 Luis Díez-Picazo, El contenido de la relación obligatoria, 17 Anuario de Derecho Civil, n. ${ }^{\circ}$ 2, 349-366 (1964); II Luis Diez-Picazo, Fundamentos del Derecho Civil patrimonial. Las relaciones obligatorias, op. cit., 64 y 113.

66 Así lo destaca Antonio Manuel Morales Moreno, op. cit., 81. Igualmente, Álvaro Vidal Olivares, Cambio de paradigma en el incumplimiento, op. cit., 154.

67 Puede verse en la doctrina española y chilena los primeros planteamientos relativos a la necesidad de adoptar una noción amplia y objetiva de incumplimiento en: Fernando Pantaleón Prieto, Las nuevas bases de la responsabilidad contractual, Anuario de Derecho Civil, n. ${ }^{\circ}$ 46, 1719-1746 (1993); Antonio Manuel Morales Moreno, Evolución del concepto de obligación en el derecho español, op. cit., 32 a 33; en Chile: Álvaro Rodrigo Vidal Olivares, Cumplimiento e incumplimiento contractual en el Código Civil. Una perspectiva más realista, op. cit., 48. Carlos Pizarro Wilson, op.cit., 399 a 400; y Claudia Mejías Alonzo, El incumplimiento contractual y sus modalidades, op. cit., 459-478; Hugo Cárdenas Villarreal \& Ricardo Reveco Urzúa, Remedios contractuales. Cláusulas, acciones y otros mecanismos de tutela del crédito, 63-66 (Thomson Reuters, 2018).

68 Konrad Zweigert \& Heinz Kötz, An Introduction to Comparative Law, 503 (3.a ed., Tony Weir trad., Oxford University Press, 1996). Como bien lo destaca Morales Moreno: "La caracterización de la vinculación contractual como garantía de un resultado (el que en cada caso debe alcanzar el acreedor) que corre a cargo del deudor, caracterización a la que se refieren Zweigert/Kotz, creo que ha traspasado las fronteras del Common Law y constituye hoy la clave esencial de modernización del Derecho de las obligaciones contractuales. Ha sido decisivo que este nuevo modelo constituyera la base dogmática bajo cuya pauta fue redactada la CISG, porque la influencia de la CISG ha sido muy poderosa. Es, también, muy importante que el nuevo modelo esté siendo la pauta de tratamiento del incumplimiento y del sistema de remedios en los diferentes textos normativos que proponen principios modelo (Principios UNIDROIT, PECL, DCFR). Todos estos materiales deben ser considerados, porque, con sus diferencias, que no inciden en el aspecto medular, desenvuelven el nuevo sistema de la vinculación contractual, y del incumplimiento del contrato y sus consecuencias". Antonio Manuel Morales Moreno, op. cit., 82.

69 María Luisa Palazón Garrido, op. cit., 16 a 17. La autora agrega que "Así ocurre en el Derecho anglo - americano, en los textos de Derecho uniforme y en el sistema alemán reformado, frente a los ordenamientos tributarios del Código civil francés, que regulan la materia de un modo fragmentario, desplazando, por ejemplo, la resolución del contrato a la sede de las obligaciones contractuales, por entender que el derecho a resolver constituye una condición resolutoria implícita en las obligaciones recíprocas".

70 Para la justificación de la opción a favor del acreedor, véase: Álvaro Rodrigo Vidal Olivares, Cumplimiento e incumplimiento contractual en el Código Civil. Una perspectiva más realista, op. cit., 522 a 528.

71 Álvaro Vidal Olivares, Cambio de paradigma en el incumplimiento, op. cit., 154. Iñigo De la Maza \& Álvaro Vidal, op. cit., 142 a 143.

72 Íd.

73 En la doctrina chilena, con un raciocinio que cabe perfectamente también en el Derecho colombiano: Claudia Mejías Alonzo, El incumplimiento resolutorio en el Código Civil, 113 (Pontificia Universidad Católica de Valparaíso, Legal Publishing, 2011).

74 Según se ha postulado ya en: Jorge Oviedo Albán, op. cit., 211-212. Véase también: Claudia Mejías Alonzo, op.cit., 116; Carlos Pizarro Wilson, op.cit., 400. Iñigo de la Maza Gazmuri, El régimen de los cumplimientos defectuosos en la compraventa, 39 Revista Chilena de Derecho, n. 3, 629-663 (2012). En la doctrina española Ángel Carrasco Perera, también señala que una prestación que adolezca de vicios ocultos es una prestación que viola el principio de identidad e integridad del pago previsto en el artículo 1157 C.C. esp., que equivale a la norma comentada del Código Civil colombiano. Ángel Carrasco Perera, op. cit., 842; Fueyo entiende que este principio presupone la interpretación e integración del contrato: Fernando Fueyo Laneri, op. cit., 126; También: Antonio Vodanovic, Derecho Civil. Tratado de las obligaciones, basado en las explicaciones de los profesores de la Universidad de Chile Arturo Alessandri Rodríguez y Manuel Somarriva Undurraga, 291 (Editorial Jurídica de Chile, 2004); Ramón Meza Barros, Manual de Derecho Civil, 342 (9.a ed., Editorial Jurídica de Chile, 2002). En contra, limitándolo al tenor literal de la declaración de voluntad II René Abeliuk Manasevich, Las obligaciones, op. cit., 739-740.

75 (artículos 1613 y 1614 CC). También véanse a partir del Código Civil chileno, los comentarios de Claudia Mejías Alonzo, El incumplimiento contractual y sus modalidades, op. cit., 476 a 477, que resultan también válidos para el Derecho colombiano.

76 Claudia Mejías Alonzo, op. cit., 119.

77 Álvaro Rodrigo Vidal Olivares, Cumplimiento e incumplimiento contractual en el Código Civil. Una perspectiva más realista, op. cit., 501 a 502. Acerca de la vinculación entre las nociones de cumplimiento e incumplimiento: Jorge Baraona Gónzalez, El retraso en el cumplimiento de las obligaciones, 89 (Dykinson, 1998); II René Abeliuk Manasevich, Las obligaciones, op. cit., 923; Carlos Pizarro Wilson, op. cit., 400. 
78 Antonio Manuel Morales Moreno, Artículo 35, en La compraventa internacional de mercaderías. Comentario de la Convención de Viena, 290 (Luis Diez-Picazo y Ponce de León eds., Civitas, 1998); Antonio Manuel Morales Moreno, Evolución del concepto de obligación en el derecho español, op. cit., 21. En esta perspectiva, en la doctrina chilena, Mejías Alonzo, quien afirma que la prestación no sólo incluye la ejecución de la actividad preestablecida en la obligación, sino también se le puede exigir toda aquella actividad que sea necesaria para alcanzar el resultado en ella previsto. Claudia Mejías Alonzo, El incumplimiento contractual y sus modalidades, op. cit., 471 a 472. Claudia Mejías Alonzo, op. cit., 102. Señala la autora que el deudor ejecuta la prestación, no sólo cuando da, hace o no lo convenido sino cuando la conducta desplegada coincide con el objeto idealmente trazado al celebrar el contrato. Claudia Mejías Alonzo, op. cit., 102.

79 II Luis Diez-Picazo, Fundamentos del Derecho Civil patrimonial. Las relaciones obligatorias, op. cit., 541.

80 Íd., 572.

\section{Licencia Creative Commons CC BY 4.0}

Cómo citar este artículo: Jorge Oviedo Albán \& Álvaro Vidal Olivares, El concepto unitario de incumplimiento en el moderno derecho de contratos, 69 Vniversitas (2020). https://doi.org/10.11144/Javeriana.vj69.cuim 